\title{
The rise of multiple institutional affiliations in academia
}

\author{
Hanna Hottenrott ${ }^{1}$ (1) | Michael E. Rose ${ }^{2}$ ( ) | Cornelia Lawson ${ }^{3}$
}

${ }^{1}$ Technical University Munich, Munich, Germany

${ }^{2}$ Max Planck Institute for Innovation and Competition, Munich, Germany

${ }^{3}$ Alliance Manchester Business School, University of Manchester,

Manchester, UK

\section{Correspondence}

Hanna Hottenrott, Technical University

Munich, 80333 Munich, Germany.

Email: hanna.hottenrott@tum.de

\section{Funding information}

Deutsche Forschungsgemeinschaft, Grant/ Award Number: HO5390/1-1

\begin{abstract}
This study provides the first systematic, international, large-scale evidence on the extent and nature of multiple institutional affiliations on journal publications. Studying more than 15 million authors and 22 million articles from 40 countries we document that: In 2019, almost one in three articles was (co-)authored by authors with multiple affiliations and the share of authors with multiple affiliations increased from around $10 \%$ to $16 \%$ since 1996 . The growth of multiple affiliations is prevalent in all fields and it is stronger in high impact journals. About $60 \%$ of multiple affiliations are between institutions from within the academic sector. International co-affiliations, which account for about a quarter of multiple affiliations, most often involve institutions from the United States, China, Germany and the United Kingdom, suggesting a core-periphery network. Network analysis also reveals a number communities of countries that are more likely to share affiliations. We discuss potential causes and show that the timing of the rise in multiple affiliations can be linked to the introduction of more competitive funding structures such as "excellence initiatives" in a number of countries. We discuss implications for science and science policy.
\end{abstract}

\section{1 | INTRODUCTION}

Institutions have an important role in academic research. They impact researchers' work as they control access to resources, networks and research infrastructure, and thus partially determine scientific discovery (Stephan, 2012). Institutional affiliation moreover affects the value ascribed to individual researchers through institutional prestige, with consequences for research and career trajectories. Science policy has further lifted the value assigned to institutions, through the use of domestic and international rankings and the introduction of performance-based institutional funding mechanisms which it believes will encourage greater research performance (Salmi, 2016).

We suggest that as a consequence of the inflated importance of affiliations, more academics are now affiliated to multiple institutions and are reporting these on their academic work. Yet, so far multiple affiliations (or co-affiliations), where researchers are formally attached to more than one institution at the same time (Hottenrott \& Lawson, 2017; Katz \& Martin, 1997), are largely unexplored. A three country and three field study conducted by Hottenrott and Lawson (2017) provides some first evidence on the extent and

We are grateful to Stefano Baruffaldi and seminar participants at Max Planck Institute for Innovation and Competition, the Leibniz Center for Science and Society (LCSS) as well as the Ludwig Maximilian University Munich for valuable feedback. Carolin Formella, Iliana Radeva, Nurzhan Sapargali, and Kaan Uctum provided valuable research assistance.

This is an open access article under the terms of the Creative Commons Attribution-NonCommercial-NoDerivs License, which permits use and distribution in any medium, provided the original work is properly cited, the use is non-commercial and no modifications or adaptations are made.

(c) 2021 The Authors. Journal of the Association for Information Science and Technology published by Wiley Periodicals LLC on behalf of Association for Information Science and Technology. 
structure of multiple affiliations, showing an increase in the three countries and scientific fields under study. Matveeva and Ferligoj (2020) reported an increase also for Russia. In this article, we expand on this prior research. In an analysis of a set of 40 countries over a 24 year time period we focus on international differences in multiple affiliations, which are important to understand potential drivers and consequences of this phenomenon.

There are a number of reasons why multiple affiliations may occur and which may explain why they differ internationally. For one, they may be driven by individual research trajectories. A prestigious affiliation can serve as a "mechanism for cumulative advantage" (Way, Morgan, Larremore, \& Clauset, 2019) and researchers may seek out affiliations to institutions outside their main employment to gain or maintain access to resources and networks. For instance, many science systems have prominent public research organizations (PROs) that contribute substantially to research production, but not teaching. The prestige and high level of research infrastructure available at these PROs make them attractive for academics at universities. Moreover, in a number of countries PRO affiliation is encouraged or linked to professorial posts. For instance, the Chinese Academy of Science which offers affiliation to leading Chinese scientists and has more than 50,000 members is listed as the top publishing institution on Nature Index, ${ }^{1}$ a database of author affiliations on articles in selected top journals (Li, 2016). Further, in internationalized research with high levels of mobility, diaspora networks form (Meyer \& Wattiaux, 2006; Miguelez \& Noumedem Temgoua, 2020). Such networks may be informal or formal, and can include association with learned societies, visiting positions, or dedicated diaspora initiatives in the home country (Baruffaldi \& Landoni, 2012). Institutions and mobile researchers may formalize these linkages in multiple affiliations to enable knowledge exchange and curb the effects of brain drain. Such international linkages could be particularly important for the Global South to redress inequalities in research production (Langa, 2018).

The importance of domestic research and diaspora differ between countries and therefore the prevalence and types of multiple affiliations differ too. Hottenrott and Lawson (2017), for instance, find in a sample of articles drawn from the Web of Science that international co-affiliations are dominant for academic authors in the United Kingdom, while cross-sector co-affiliations are more common in Japan. This reflects the importance of internationalized communities and domestic PROs respectively, and providing first clues towards the international differences we may observe.

Any increases in multiple affiliations, however, will not be entirely due to individual research trajectories. Rankings and research assessments, mentioned above, can also be a cause for the increase of multiple affiliations, and could provide an explanation for why they may differ internationally. Specifically, any country differences in multiple affiliations may be due to the shift in some countries towards initiatives designed to improve their competitiveness in international research. Some countries recently implemented major reforms in the resource allocation processes within the research sector, moving towards performance-based allocation of funding through schemes such as research excellence initiatives (ExIns). These initiatives aim to accelerate the transformation of higher education and to boost the research capacity and productivity of academic institutions (Salmi, 2016). This is achieved via block grants being made available to selected institutions or for the establishment of new centers of excellence such as in the case of Germany, or via research evaluation such as the Research Excellence Framework in the United Kingdom (Geuna \& Piolatto, 2016; Salmi, 2016). ExIns thus introduce competition and performance-based funding elements into higher education systems, which are said to increase performance (Aghion, Dewatripont, Hoxby, Mas-Colell, \& Sapir, 2014), and are arguably the most important factor for universities to move up in global rankings (Benito, Gil, \& Romera, 2019). Sources of such performance change other than the monetary investments are the concentration of resources, focus on measurable research outputs, and orientation towards international research agendas and publication outputs, which contribute towards higher international visibility (Salmi, 2016). There is substantial existing evidence on the impact of ExIns on publication output, for example from China's 985 project (Zhang, Patton, \& Kenney, 2013; Zong \& Zhang, 2019), Russia's 5100 project (Agasisti, Shibanova, Platonova, \& Lisyutkin, 2020; Turko, Bakhturin, Bagan, Poloskov, \& Gudym, 2016), Germany's Excellence Initiative (Civera, Lehmann, Paleari, \& Stockinger, 2020; Menter, Lehmann, \& Klarl, 2018) or Taiwan's World Class University project (Fu, Baker, \& Zhang, 2020), which provide evidence of positive, but also mixed performance effects of these initiatives.

Multiple affiliations may increase as a consequence of ExIns for a number of reasons. ExIns are closely linked to research assessment and an expectation of performance improvement. Universities in an attempt to upgrade quickly, may buy in external talent instead of building up capacity locally or restructure their activities. In Russia, for instance, a performance effect from ExIns was quickly observed, as was an increase in multiple affiliations (Matveeva \& Ferligoj, 2020), suggesting that universities hired external talent. Such co-affiliations were potentially aimed at a quick increase in rankings based on bibliometric data. In France, in turn, research and teaching activities needed to be concentrated "under one roof and one name" to build greater visibility in international rankings (Paradeise, 2018), achieved via a closer integration of universities and CNRS research 
centers. In this context multiple affiliations are an outcome of formalized or institutionalized forms of collaborations (Hicks \& Katz, 1996), which have also emerged as an explicit goal of ExIns in some countries, such as Germany's Clusters of Excellence (Bornmann, 2016; Froumin \& Lisyutkin, 2015).

There is also some evidence that ExIns aimed at elite institutions may not only improve the international ranking of "excellence" universities (Benito et al., 2019; Salmi, 2016), but that they can lift other, unfunded institutions (Agasisti et al., 2020; Civera et al., 2020; Fu et al., 2020). The increase in stratification associated with ExIns and the concentration of resources make emerging elite institutions very attractive for outside researchers. Academics at lower ranked institutions may thus seek access to the resources available there. Hamann (2018) for instance shows more inward mobility into high-rank institutions following a research evaluation round in the United Kingdom. In addition, the metrics that determine resource allocation also serve as a reference point for lower ranked or unfunded institutions, who may adopt similar strategies in an attempt to improve their position in future evaluation or funding rounds.

Despite first tentative findings, there is need for a better understanding of the extent and nature of multiple affiliations and how they may relate to research excellence initiatives in different countries. In particular, there is a lack of a complete comparison of multiple affiliation trends within research nations, especially those that implemented ExIns. To fill this gap, this study sets out to answer the following three research questions:

- RQ1: How have multiple affiliations evolved over time in different countries and scientific fields?

- RQ2: Do we observe any patterns in the geographic location and in the sectors of co-affiliations?

- RQ3: Do country differences in the evolution of multiple affiliations relate to policy changes in funding allocation (ExIns) in different countries?

To investigate the change of multiple affiliations over time we present a large-scale bibliometric analysis that makes use of the affiliation information of 15,234,353 different authors located in 40 countries. All data originate from Scopus. We use 22,198,910 research articles published between 1996 and 2019 that are representative for 26 distinct scientific fields.

The use of publication affiliation data to investigate multiple affiliations is not only appropriate but also highly relevant, as it is used frequently to assign research achievements to scientific institutions, such as with university rankings (Geuna \& Piolatto, 2016). For example, the Times Higher Education ranking since 2016 uses Scopus data for its popular THE World University Rankings. ${ }^{2}$ This is not without problem. If not accounting for multiple affiliations, each document counts as often as there are distinct affiliations reported on the publication. A simple example shows that distortions arise easily. Consider university $U$ with 4 researchers, research institute $R$ with 2 researchers, and College $C$ with 3 researchers. If each researcher publishes one article, the ranking obtains as $U>C>R$. If however two of $U$ 's researchers have a multiple affiliation with $R$, the ranking changes to $U>R>C$. As such the reliance of research rankings on bibliometric data could create incentives for institutions to offer affiliations to researchers primarily employed elsewhere. Evidence comes from Bornmann and Bauer (2015), who analyze the affiliations of highly cited authors and find that Saudi Arabia emerges high in the country ranking when secondary affiliations are counted. As a consequence, research discoveries may be assigned to places where they did not necessarily originate (Bhattacharjee, 2011; Xin, 2006). In the example above, did $R$ or did $U$ enable the research of the two researchers that hold multiple affiliations at both $R$ and $U$, or did both contribute? While this is not a question we are able to answer, it is one that emphasizes the relevance of investigating multiple affiliations.

Our study thus contributes towards a better understanding of multiple affiliations which will also inform how we think about creative places and will thus ultimately impact science policy (de Rijcke \& Rushforth, 2015; Hicks \& Katz, 1996).

\section{2 | METHODS}

\section{1 | Data collection}

We base our analysis of affiliations on documents published between 1996 and 2019. ${ }^{3}$ Counting affiliations from published articles has the advantage of being available at a large scale and with high coverage (as opposed to, for example, CVs or university websites). We derive all data from Scopus which has three important advantages over other indexing systems: comprehensive coverage of scientific articles (Mongeon \& Paul-Hus, 2016), disambiguation of authors and their affiliations along with the assignment of unique Author IDs, and the availability of additional information on institution addresses (e.g., country and organization type).

We study all 26 scientific fields as identified by the All Science Journal Classification (ASJC) codes excluding the category "Multidisciplinary." Table 1 lists these together with the number of papers and authors used. The analysis focuses on 40 countries: All OECD countries as of 2019 excluding Latvia, Luxembourg and Iceland (because they host too few universities), and a group of 
TA B LE 1 Number of journals, authors and articles used in the study, by field

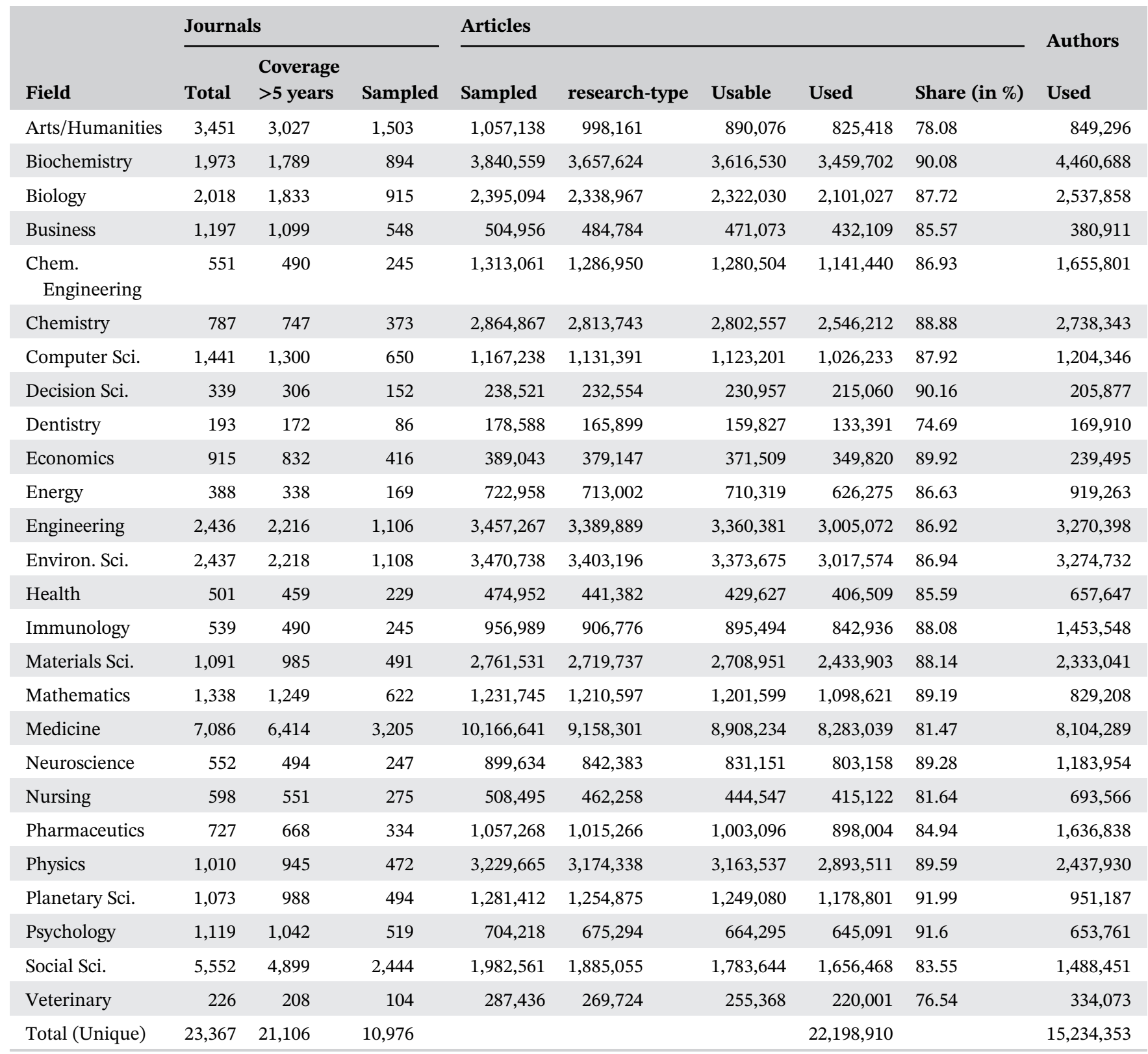

Note: The table reports steps of the sampling and selection process. For each field, we select all journals with at least 6 years of publication history in the 19962019 period according to Scopus. Of these we restrict to journals in the upper half of the SJR indicator distribution as of 2019. For each journal, we deduct nonresearch type documents, documents with missing author and affiliation information ("Usable"), and finally documents where all authors are from countries outside our sampling frame. Column "Share" reports the share of "Used" documents over "Sampled" documents. Column "Authors Used" reports the number of unique authors of the "Used" documents.

non-OECD science producing countries consisting of Argentina, China, Romania, Russia, Singapore, South Korea, South Africa, and Taiwan.

We obtain the set of articles that represent a field through the SCImago Journal Rank (SJR) indicator. The SJR indicator is a "size-independent indicator of journals" scientific prestige' and is also based on the Scopus database (González-Pereira, Guerrero-Bote, \& Moya-Anegón, 2010). ${ }^{4}$ For each field we first remove journals with fewer than three citations in any year $t$ during the previous 3 years and we remove sources with less than 6 years of coverage in the 1996-2019 period. In each of the 26 ASJC fields, we drop journals with below-median SJR indicator in each field. Thus, we consider only the top 50\% of journals in each ASJC field. If journals are assigned to multiple fields, we also assign articles published therein to multiple fields. Forty-three percent of journals list more than one field and on average each journal belongs to 1.63 fields, with eight fields being the maximum. We then retrieve bibliometric information for all articles published in these journals during the 1996-2019 period using the "pybliometrics" 
module developed by Rose and Kitchin (2019). ${ }^{5}$ This stage excludes articles authored by either anonymous authors or collaborative units.

Next, we remove observations with missing affiliations ${ }^{6}$ and mark an article "usable" if it provides affiliation information for at least one author. The share of articles with "usable" affiliations is close to $100 \%$ in the majority of fields and increasing over time (Figure A1). Articles are further removed if: they are not research-type articles (e.g., editorials, reviews, etc.), the author and/or affiliation information is completely absent, or none of an article's authors is from the selected set of countries. Unique authors are then identified based on their Scopus Author ID. ${ }^{7}$

Table 1 outlines this sampling and selection strategy. For each field we list the total number of journals available, the number of journals sampled following the selection described above, the number of articles sampled and finally used, and the number of authors on these articles. The largest number of journals is selected in the field of Medicine $(3,205)$ and the fewest in Dentistry (86). Articles can appear several times if the journal in which they are published is categorized into two or more different research fields. Authors also appear several times if they publish in multiple fields. In other words, we usually study author-field pairs to avoid assigning an author to a single field based on our own judgment.

\section{2 | Identifying multiple affiliations}

To identify multiple affiliations we use authors' affiliation information on articles in the Scopus database. ${ }^{8}$ An article is considered to be a multiple affiliation article if at least one of the authors lists multiple affiliations. When we study author-year or author-year-field observations, an author is considered to have multiple affiliations if they list more than one affiliation on at least one of their articles in that year and field. We thus consider two different measures of multiple affiliation, by article and by author.

We assume the first listed affiliation to be the main affiliation, and hence take the country of the first affiliation as "home" country of the author. Table A1 shows the number of authors and articles by country of first affiliation for the full dataset. Authors are marked as having an international affiliation if we observe a second affiliation in a country that is different from the home country.

\section{3 | Computing shares of authors with multiple affiliations}

When computing shares of authors with multiple affiliations by country and by field, there are in general two ways to do so. One way accounts for the different distribution of articles across fields in different countries (or the distribution of articles across countries), the other does not. Formally, let $a$ denote the number of authors and $a^{M}$ denote the number authors with multiple affiliations in country $c$ in field $f$ and year of publication $t$. Throughout the analysis we use the average country-year share of authors with multiple affiliations defined as:

$$
s_{c, t}=\frac{\sum a_{c, t}^{M}}{\sum a_{c, t}} .
$$

Likewise, when aggregating over fields, we can use the average share of authors with multiple affiliations per field as:

$$
s_{f, t}=\frac{\sum a_{f, t}^{M}}{\sum a_{f, t}} .
$$

Alternatively to averaging directly across countries or fields, we can average in two steps by first calculating the country-field level average share:

$$
m_{c, f, t}=\frac{\sum a_{c, f, t}^{M}}{\sum a_{c, f, t}} .
$$

and then take the average over these values either by country or field:

$$
\begin{gathered}
\bar{s}_{c, t}=\frac{m_{c, f, t}}{\sum_{c} m_{c, f, t}} . \\
\bar{s}_{f, t}=\frac{m_{c, f, t}}{\sum_{f} m_{c, f, t}} .
\end{gathered}
$$

Qualitatively both methods paint very similar pictures as shown in a comparison between Figure 1a and Figure A2.

\section{3 | RESULTS}

\section{1 | The evolution of multiple affiliations}

We firstly investigate the evolution of multiple affiliations over time to investigate RQ1. The results presented in Figure 1 and Table 2 show that multiple affiliations are a global phenomenon and that they are on the rise. 
(a)

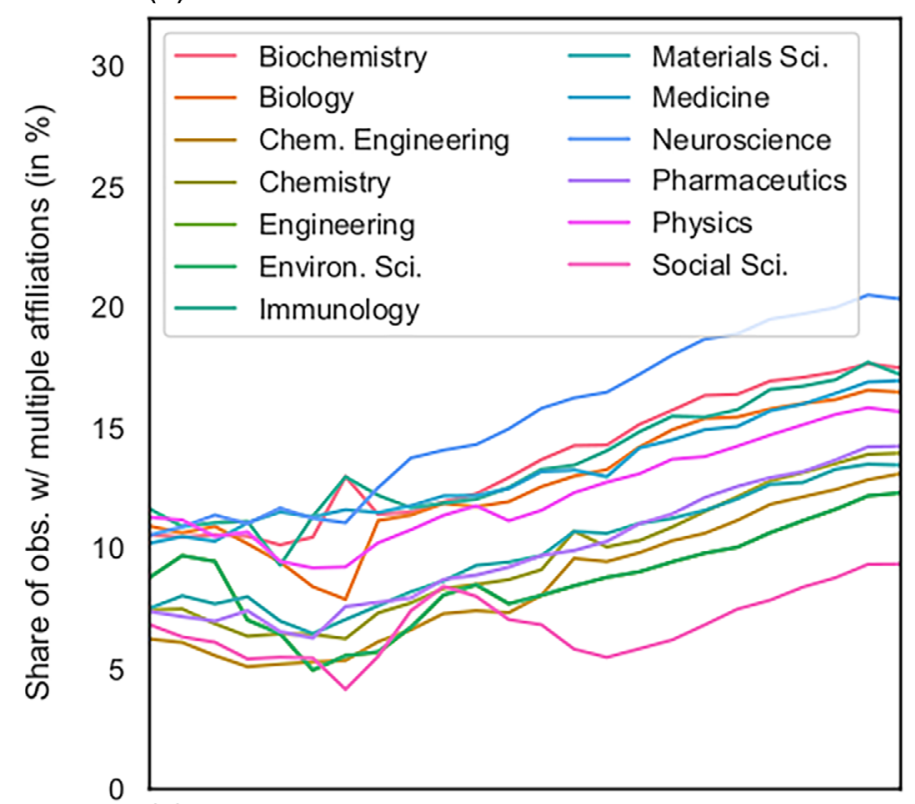

(c)

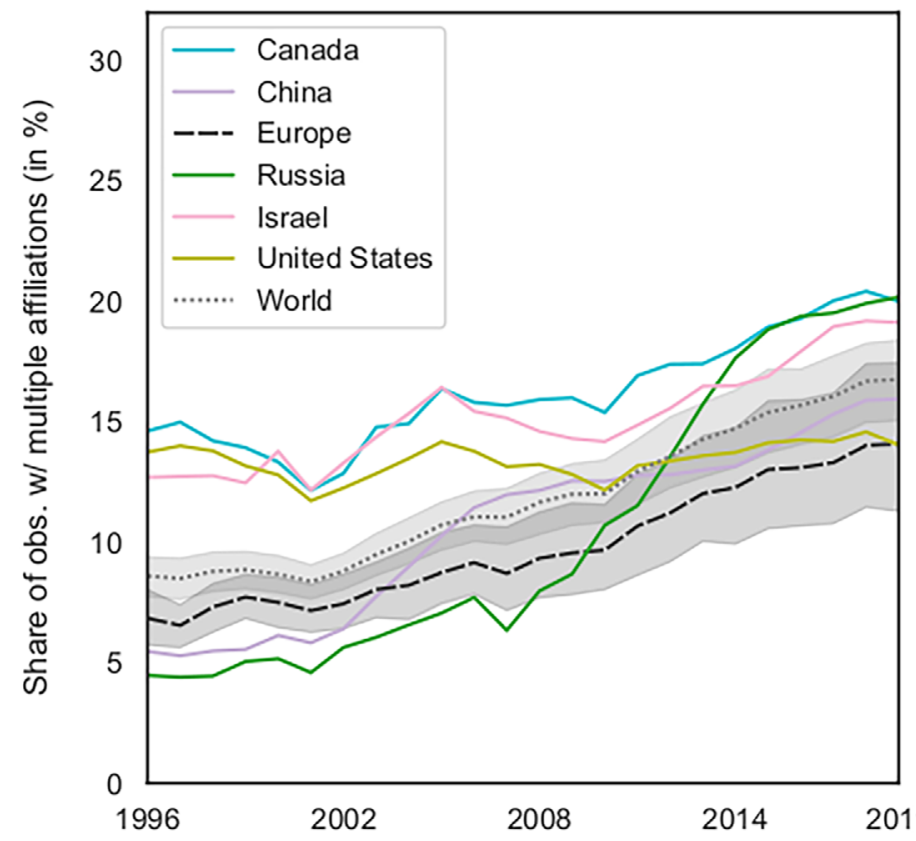

(b)

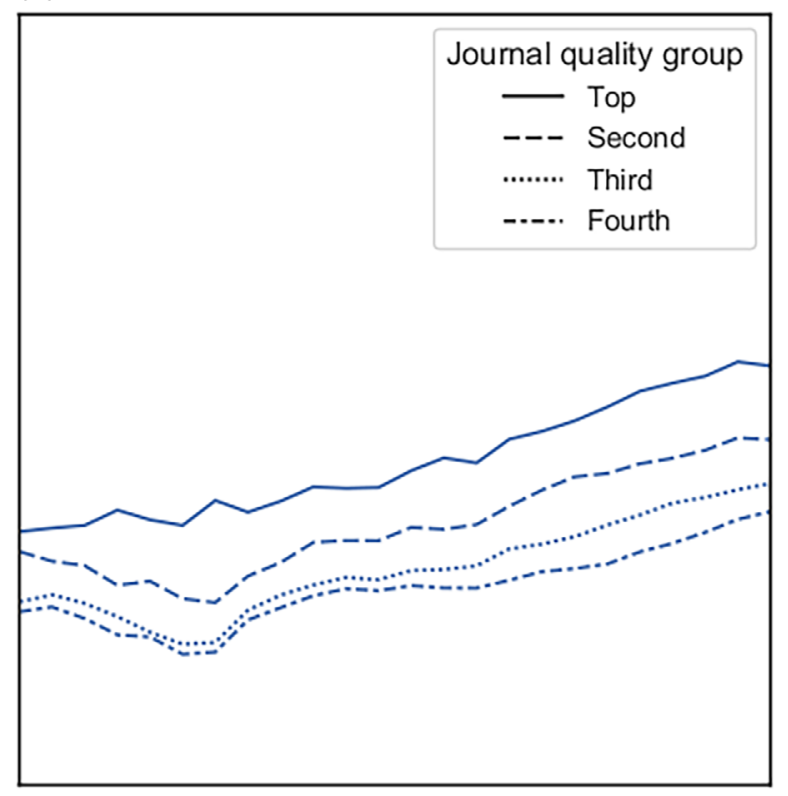

(d)

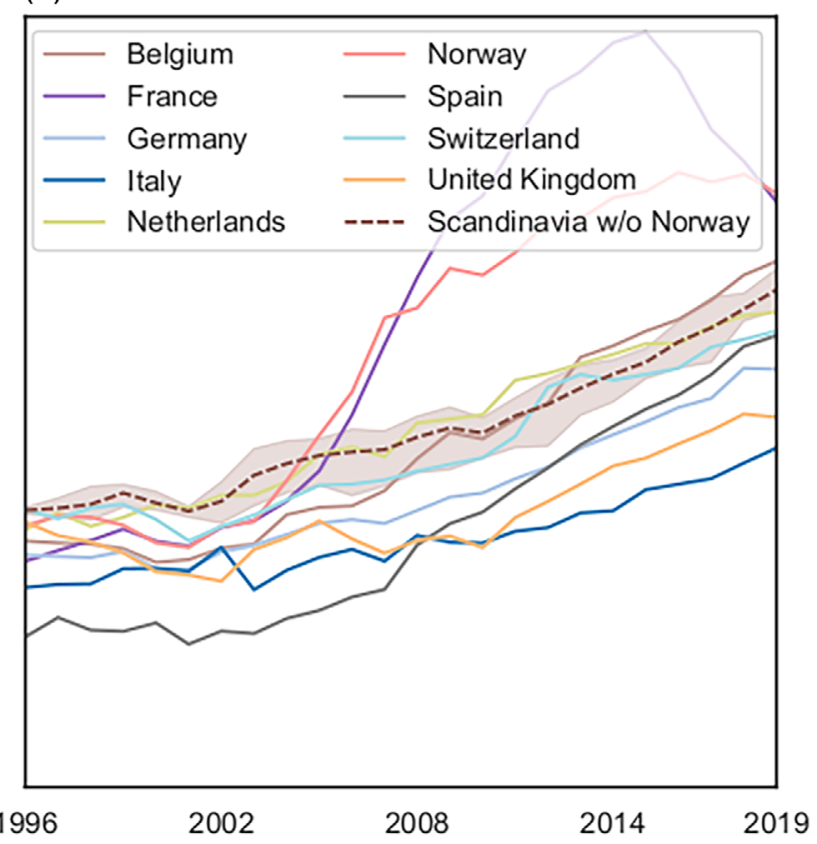

F I G U R E 1 Authors with multiple affiliations. (a) Share of authors with multiple affiliations by field. Authors are assigned to fields based on the fields to which their article's journal is assigned. Authors can appear multiple times if they publish in different years or in different fields. See Table A2 for precise values. (b) Share of authors with multiple affiliations by journal quality group. A journal quality group corresponds to a journal's quartile in the field-wise distribution of the SJR indicator. In cases where a journal is assigned to multiple fields, the higher quartile applies. See Table A3 for precise values. (c/d) Share of authors with multiple affiliations by country. Authors are assigned to the country of their first listed affiliation per publication. See Table A4 for precise values [Color figure can be viewed at wileyonlinelibrary.com]

Figure 1 shows that they have become more prevalent in all scientific fields, all journal quality groups, and the vast majority of countries. From Table 2, which reports the share of articles with at least one author with multiple affiliations by year and field, we see that, while on average about one quarter of articles qualify as having multiple affiliations, this figure was lowest in 2001 with a share of $14.7 \%$ and highest in 2018 with $32.5 \%$. While increasing in all fields, in 2019 the share of articles with at least one author with multiple affiliations is highest in Neuroscience (49.3\%) and lowest in Arts/Humanities (13.6\%).

Looking at the author level, we find that the share of authors with multiple affiliations increased from $9.8 \%$ in 


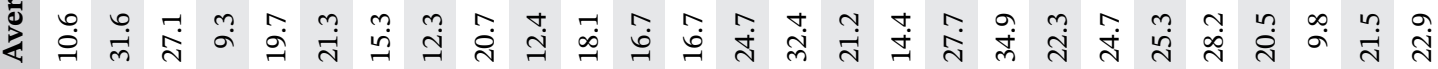

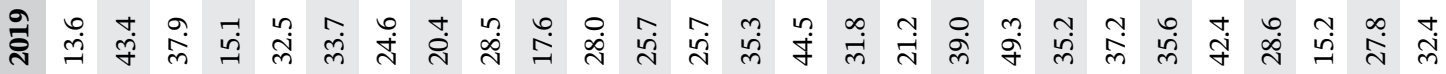

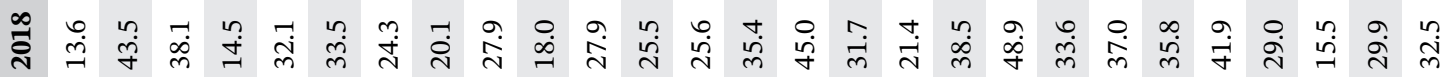

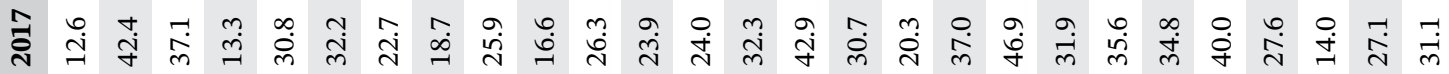

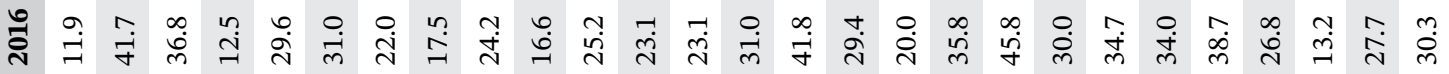

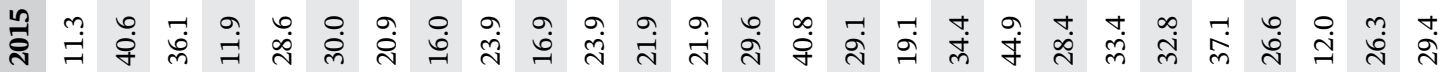

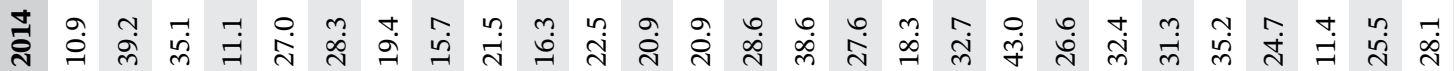

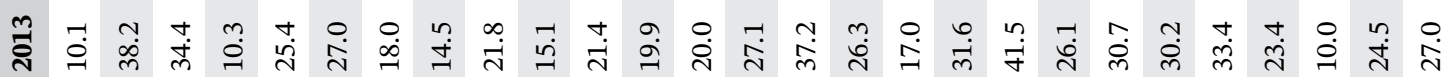

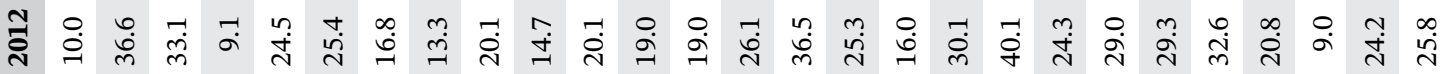

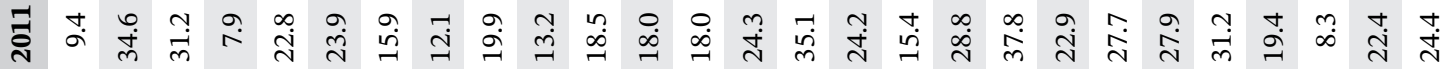
离

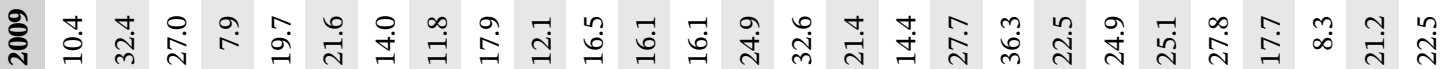

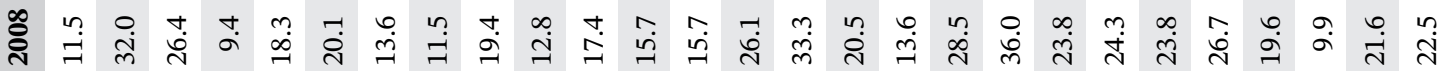

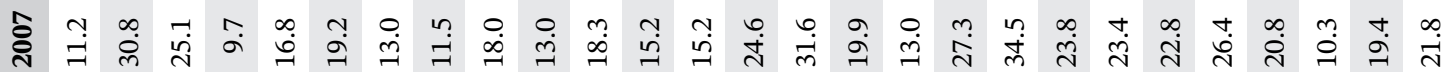

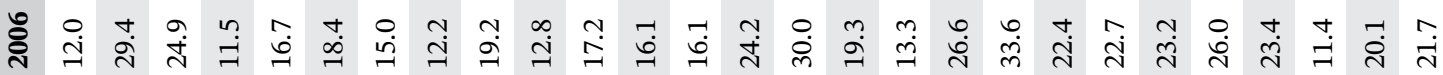

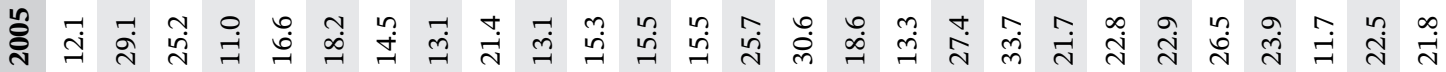

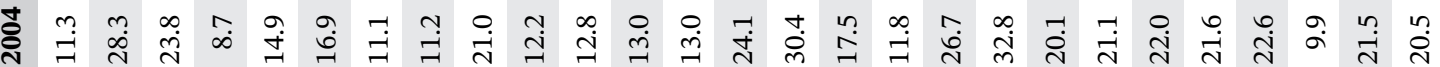

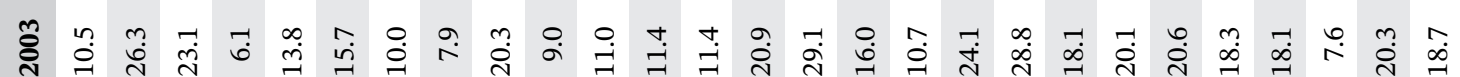

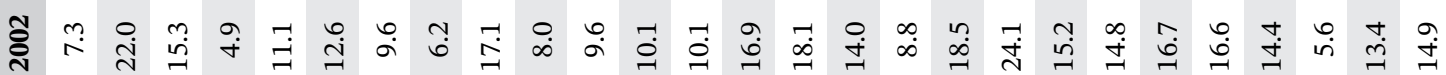
ప艹 \& gे

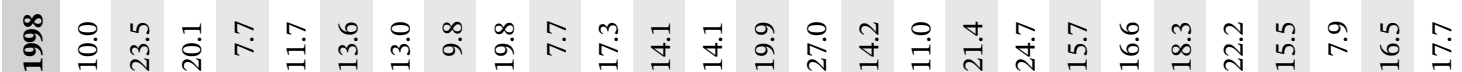

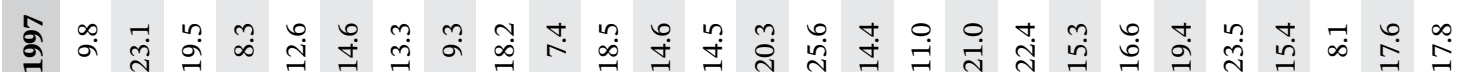

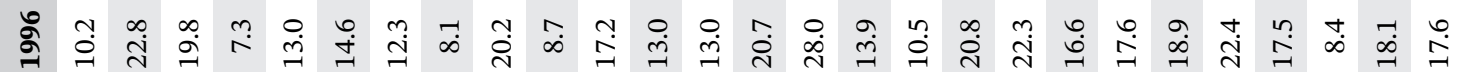
茨 
2001 to $15.9 \%$ in 2019 (see Table A2). This corresponds to an increase of more than $60 \%$. Figure 1 graphically reports how author affiliation trends differ by field, journal quality, and country. Based on 109,448,897 author-field-year observations, multiple affiliations are most common in Neuroscience $(20.3 \%$ in 2019$)$ and least common in the Social Sciences (9.3\% in 2019) (Figure 1a). Further, relying on $63,935,940$ author-journal quality group-year observations in Figure 1b, we see that the number of authors with multiple affiliations increases in all journal quality groups. A journal quality group corresponds to a journal's quartile in the field-wise distribution of the SJR indicator of the journals included in our study (the top 50\%). For example, the "Top" category is the union of top quartiles of each field's SJR indicator distribution. Based on this classification, we find that top journals have on average a higher share of authors with multiple affiliations.

Figure 1c,d reports country differences, where we distinguish the author-year observations by country of first listed affiliation (48,352,112 observations). Although there are increasing trends in multiple affiliations in most countries, we also see substantial variation. For instance, while in the United States the share of authors with multiple affiliations remains rather constant at about 9\% since 1996, the shares in other larger economies increases substantially over time. For instance, in China the share of authors with multiple affiliations experience an increase already in the late 1990s, peaking in 2005 and remaining relatively constant until 2016 (see Figure 1c). In Europe, multiple affiliations become more common relatively abruptly in the early to mid-2000s. France and Norway stand out with a steep increase and a high peak level in 2015, when more than one in four authors report multiple affiliations on their scientific articles (see Figure 1d). Indeed, the share of authors with multiple affiliations increases in nearly all countries (see Table A4 for the full list).

\section{2 | Multiple affiliations by organization type and country}

The increase in multiple affiliations globally could be reflected in increases in affiliations that span different types of organizations (or not) and national borders (or not) (RQ2).

\subsection{1 | Organization types of co- affiliations}

In Figure 2, we consider 41,119,839 author-article pairs to investigate organization type combinations in multiple affiliations. Organization types (university, research institute, hospital, governmental, non-governmental, private, other) are drawn from Scopus. Panel A shows the different combinations in multiple affiliation. Panel B, for comparison, shows the shares of organization types based on single affiliation authors, illustrating that university affiliations are by far the most common type. We can see from panel A that about half of all multiple affiliations involve either two universities or a university and a research institute. These are also the combinations that drive the global upward trend in multiple affiliations, with the latter in particular having gained in importance since the early 2000s. This suggests that there may be benefits to both researchers and academic institutions from affiliating across academic institutions. Affiliation with a university and a hospital is very frequently observed, primarily as this represents the most frequent type of co-affiliation in Medicine (26\%; see Table A6 for breakdown by field). Co-affiliations that involve governmental or non-governmental organizations (NGO) play only a very minor role. Interestingly, multiple affiliations that involve companies are also relatively rare. This is even true in fields such as Computer Sciences and Engineering. However, not all company or NGO affiliations may be recognized as such, especially if an institution is small and linked affiliations rare and therefore not identified by Scopus. Figure 2a shows a substantial share of organization type combinations involving unknown sectors which could be small firms, colleges, government bodies or NGOs. ${ }^{9}$ Yet, overall coaffiliations occur largely between academic institutions and less so with organizations outside academia.

\subsection{2 | International co-affiliations}

Multiple affiliations can moreover occur domestically and internationally. In our data, we find that the share of authors with an international co-affiliation in all authors with multiple affiliations differs strongly between countries and the time period considered. ${ }^{10}$ The left-hand panels in Figures 3 and 4 show this share for all 40 countries during the respective time periods. Color shades indicate the share of authors with multiple affiliations in all authors in each country in the same period. Comparing the two we can see that the overall importance of international co-affiliations decreases over time. In the 1996-1999 period the share of authors with an international co-affiliation in all authors with multiple affiliations ranges between 18\% for the United States and 75\% for Romania. In the 2016-2019, the shares range between $7 \%$ in Argentina and $40 \%$ in Austria, while the overall proportion of multiple affiliations increased. Indeed, the 
(a)

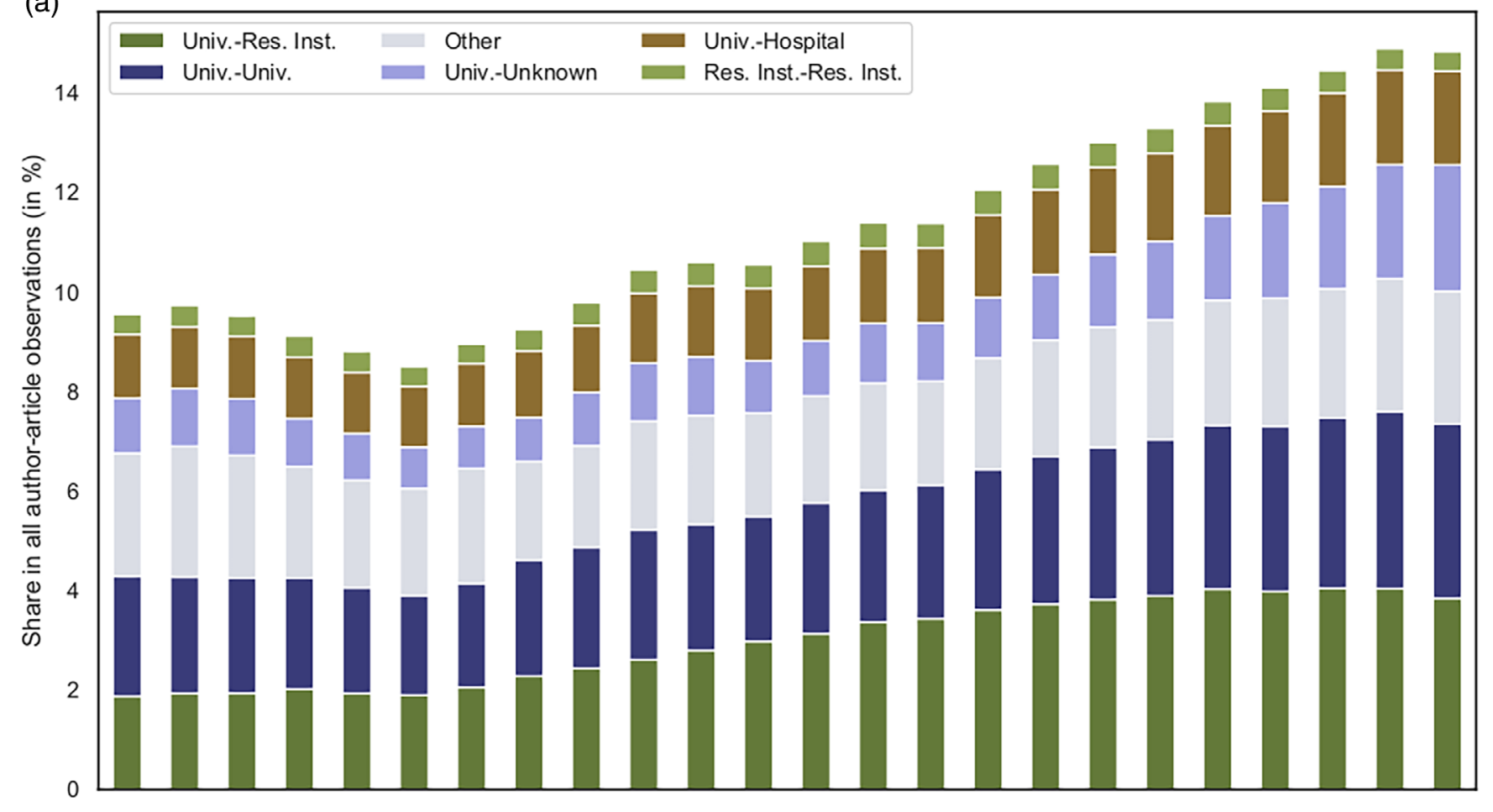

(b)

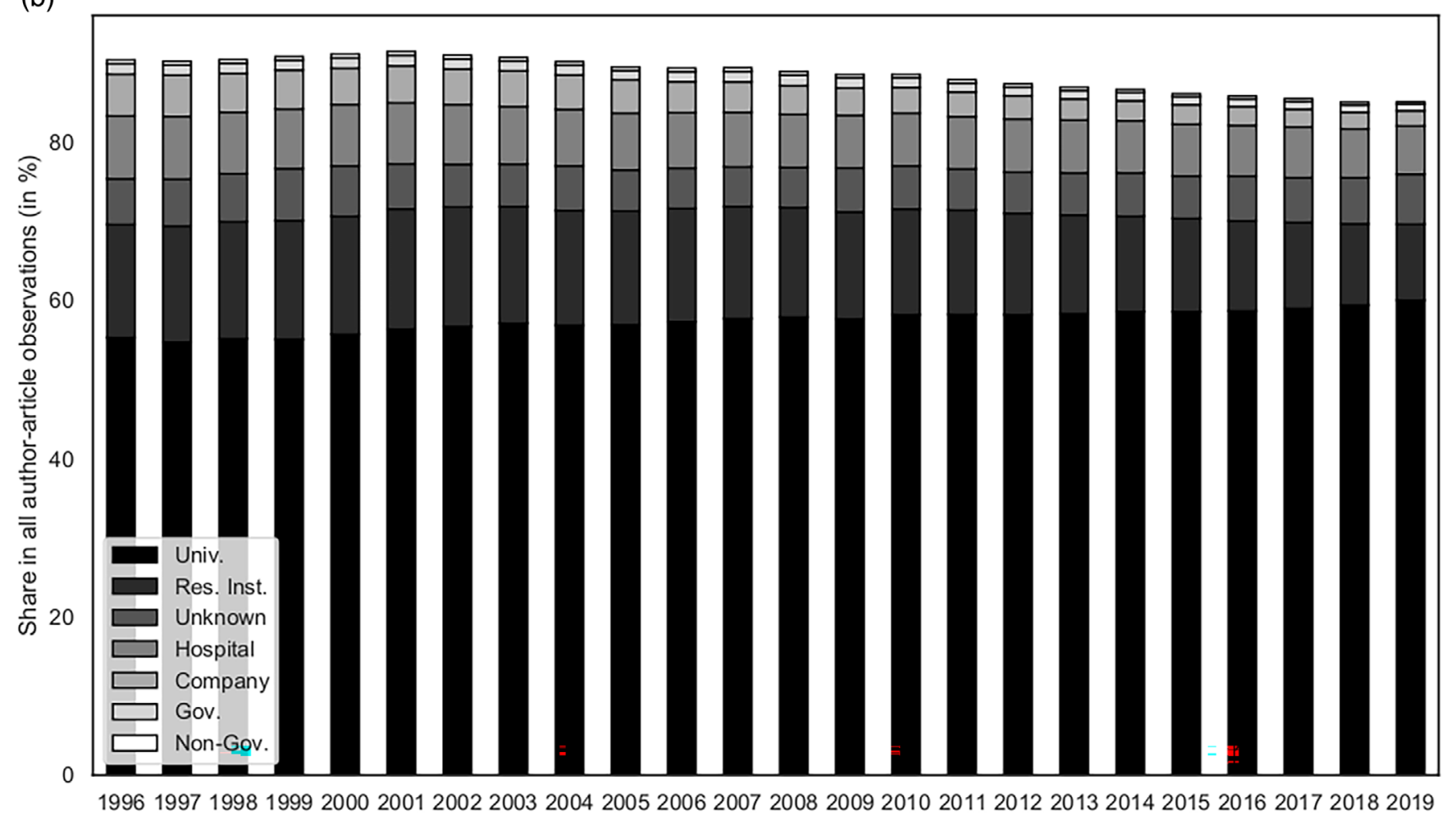

F I G URE 2 Organization type combinations. Figures depict shares in all affiliations at author-article level. Organization types are provided by Scopus. Combinations less than 3\% of all combinations in each year grouped as "Other". (a) Author-article observations with multiple affiliations. (b) Author-article observations with single affiliations. See Table A5 for precise numbers for both panels [Color figure can be viewed at wileyonlinelibrary.com]

country-level correlation between the share of authors with multiple affiliations and the share of authors with an international co-affiliation is $\rho=-0.295$ (1996-1999: $\rho=-0.380$ ), indicating that in countries where multiple affiliations are more frequent, these mainly occur domestically. 
Figures 3 and 4 moreover illustrate the importance of a small number of host countries, depicted in the righthand panels. For the majority of countries the most important host of a co-affiliation is the United States. Frequent countries among the two most important ones are China, United Kingdom and Germany. China is also the most important host for international affiliations of United States-based researchers. In some instances the most important host is a neighboring country, for example, the Netherlands for Belgium or Spain for Portugal (right part of Figure 4). Comparing the 2016-2019 period to the 1996-1999 period reveals a broadened set of host countries as China and several European countries became more prominent. Moreover, we see an overall decrease in the concentration in top partner countries: The United States and the United Kingdom remain very prominent, but several European countries, such as Germany and Spain, and particularly China emerge amongst the top 2 hosts of international affiliations in more recent years.

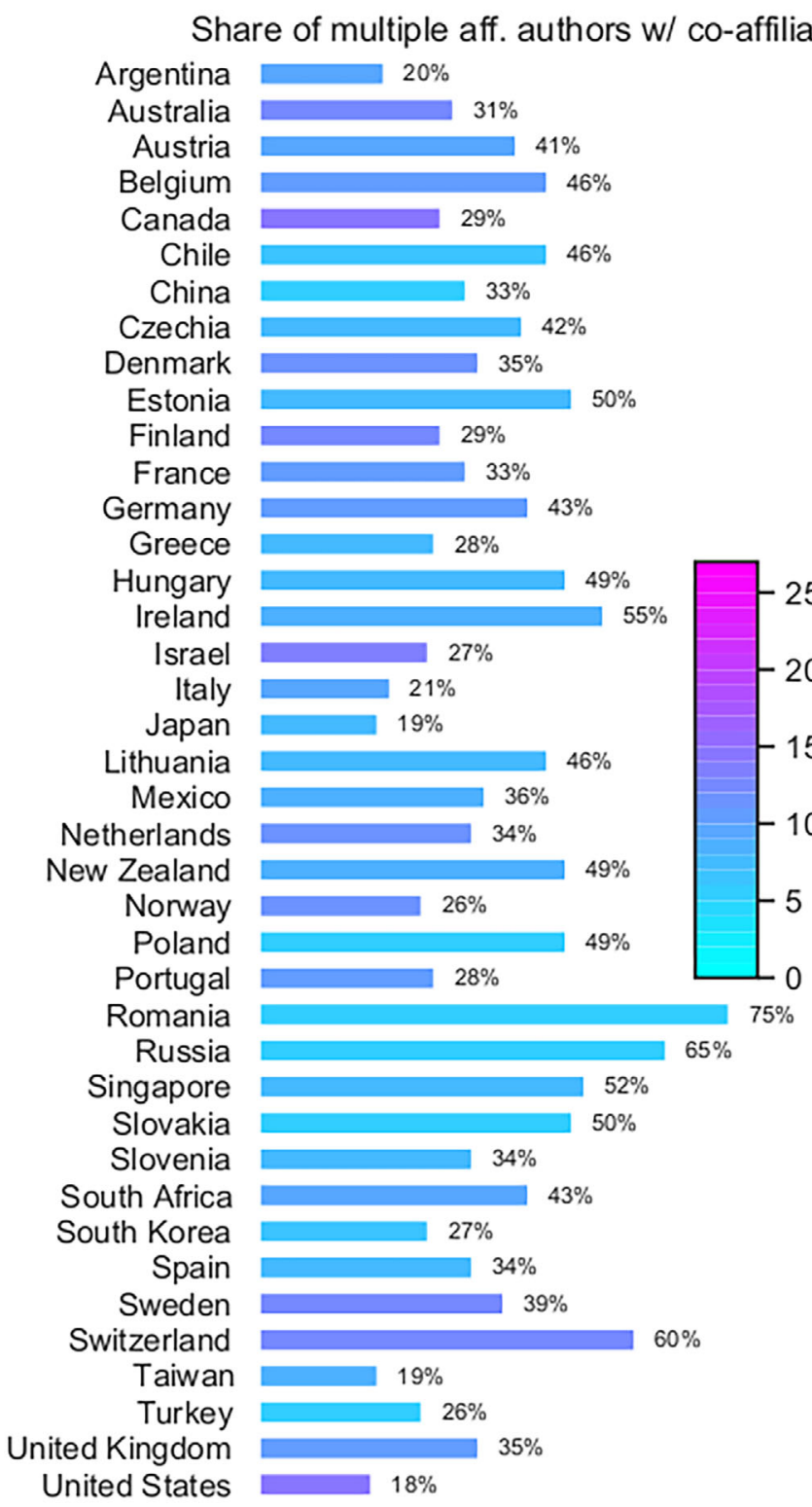

Top 2 co-affiliation host countries

\begin{tabular}{|l|l|}
\hline \multicolumn{1}{|c|}{} & United States \\
& United Kingdom \\
\hline & Germany \\
\hline & Sweden \\
\hline & France \\
\hline & Japan \\
\hline & Canada \\
\hline & Finland \\
\hline & Spain \\
\hline
\end{tabular}

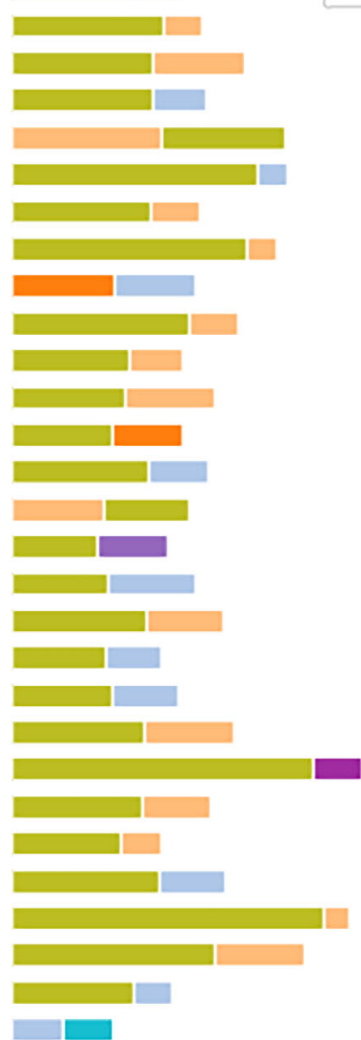

$0 \%$

$50 \%$

$100 \%$

$150 \%$

F I G U R E 3 International co-affiliations by country (1996-1999 averages). The figure depicts the shares of authors with international coaffiliations in all author-article observations with multiple affiliations (left) and the two most common host countries for these affiliations (right) for the 1996-1999 period. Reading example: Argentina has a relatively medium share of authors with multiple affiliations, of which $20 \%$ hold their second affiliation outside Argentina. In about $40 \%$ of cases the second affiliation is in the United States, in a further approx. $10 \%$ it is in Spain [Color figure can be viewed at wileyonlinelibrary.com] 
Share of multiple aff. authors w/ co-affiliation abroad

Argentina $=7 \%$

Australia $\quad 20 \%$

Austria $40 \%$

Belgium $31 \%$

Canada

Chile

China

Czechia

Denmark

Estonia

Finland

France

Germany

Greece

Hungary

Ireland

Israel

Italy

Japan

Lithuania

Mexico

Netherlands

New Zealand

Norway

Poland

Portugal

Romania

Russia

Singapore

Slovakia

Slovenia

South Africa

South Korea

Spain

Sweden

Switzerland

Taiwan

Turkey

United Kingdom

United States

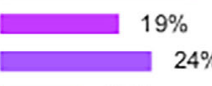

$13 \%$
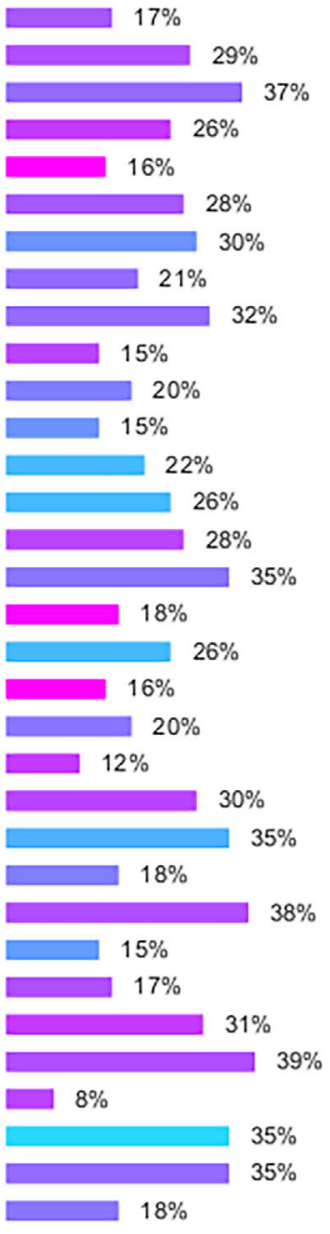

Top 2 co-affiliation host countries

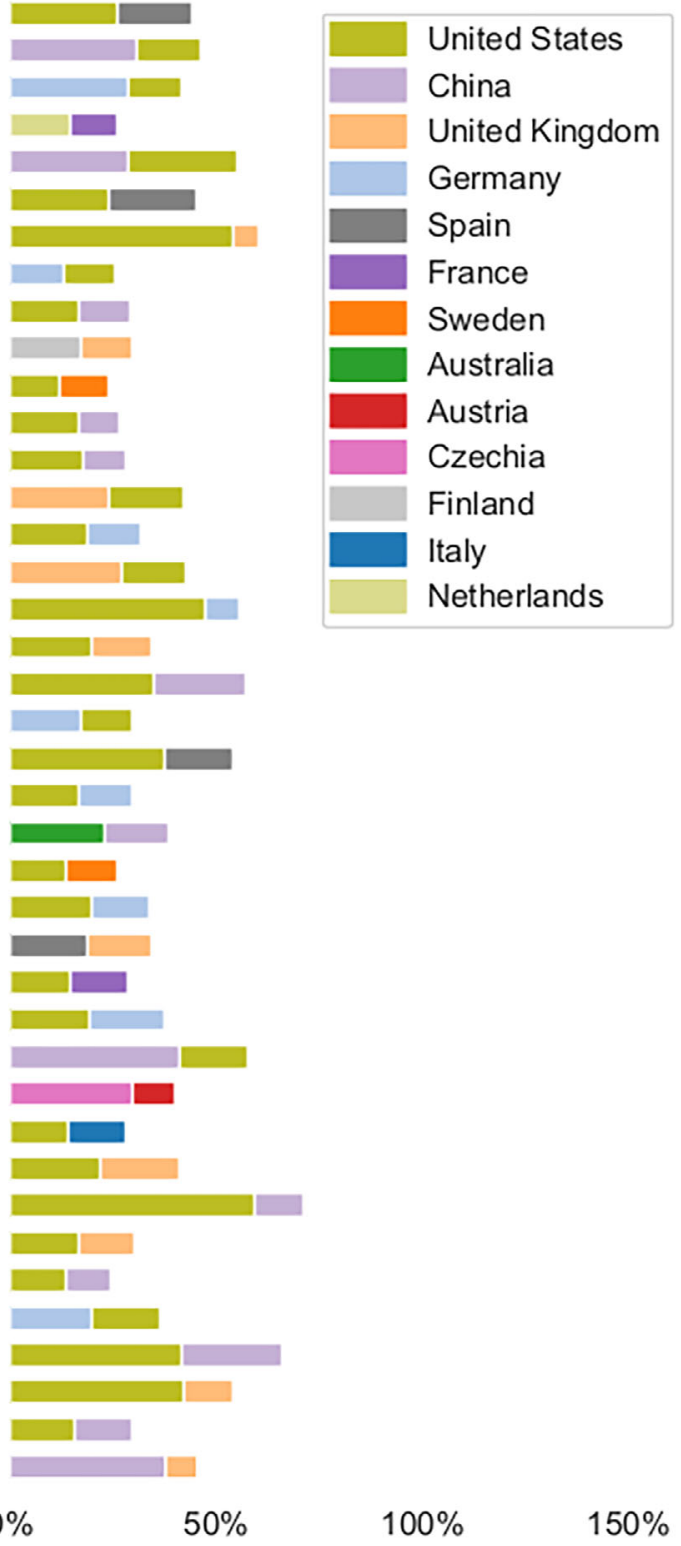

F I G U R E 4 International co-affiliation by country (2016-2019 averages). The figure depicts the shares of authors with international coaffiliations in all author-article observations with multiple affiliations (left) and the two most common host countries for these affiliations (right) for the 2016-2019 period. Reading example: Argentina has a relatively high share of authors with multiple affiliations, of which 7\% hold their second affiliation outside Argentina. In about 35\% of cases, the second affiliation is in the United States, in a further approx. 20\% it is in Spain [Color figure can be viewed at wileyonlinelibrary.com]

There are also groups of countries that tend to maintain higher levels of international co-affiliation among themselves rather than with others. Figure 5 reveals such communities according to the Leiden algorithm (Traag, Waltman, \& van Eck, 2019) based on host linkages when the link represents at least $10 \%$ of country authors with an international co-affiliation.

While almost all countries are linked to the United States, there are countries additionally (or more importantly) linked to one common country. For example,
Argentina, Chile, Mexico and Portugal are additionally linked to Spain. Sweden and France emerge as centers of small communities, while Germany is the center of a larger central European community. Interestingly China and the United States are closely interlinked as part of a largely Pacific community. While all these communities share clear geographic or language linkages, a more diverse community emerges with the United Kingdom at its center, comprising Greece, Ireland, Italy, Slovenia, and South Africa. Here we may observe the result of 
longer-term brain drain to the United Kingdom (Van Der Wende, 2015).

Figure 5 also hints at a core-periphery structure in the network, where few countries are common destinations for international co-affiliations. This is further apparent from Figures A3 and A4 which depict the information from Figures 3 and 4 in a network perspective, corroborating the central position of especially the United States, China, the United Kingdom and Germany in the 20162019 period. Other community centers, such as France and the Netherlands are rather peripheral in such a network.

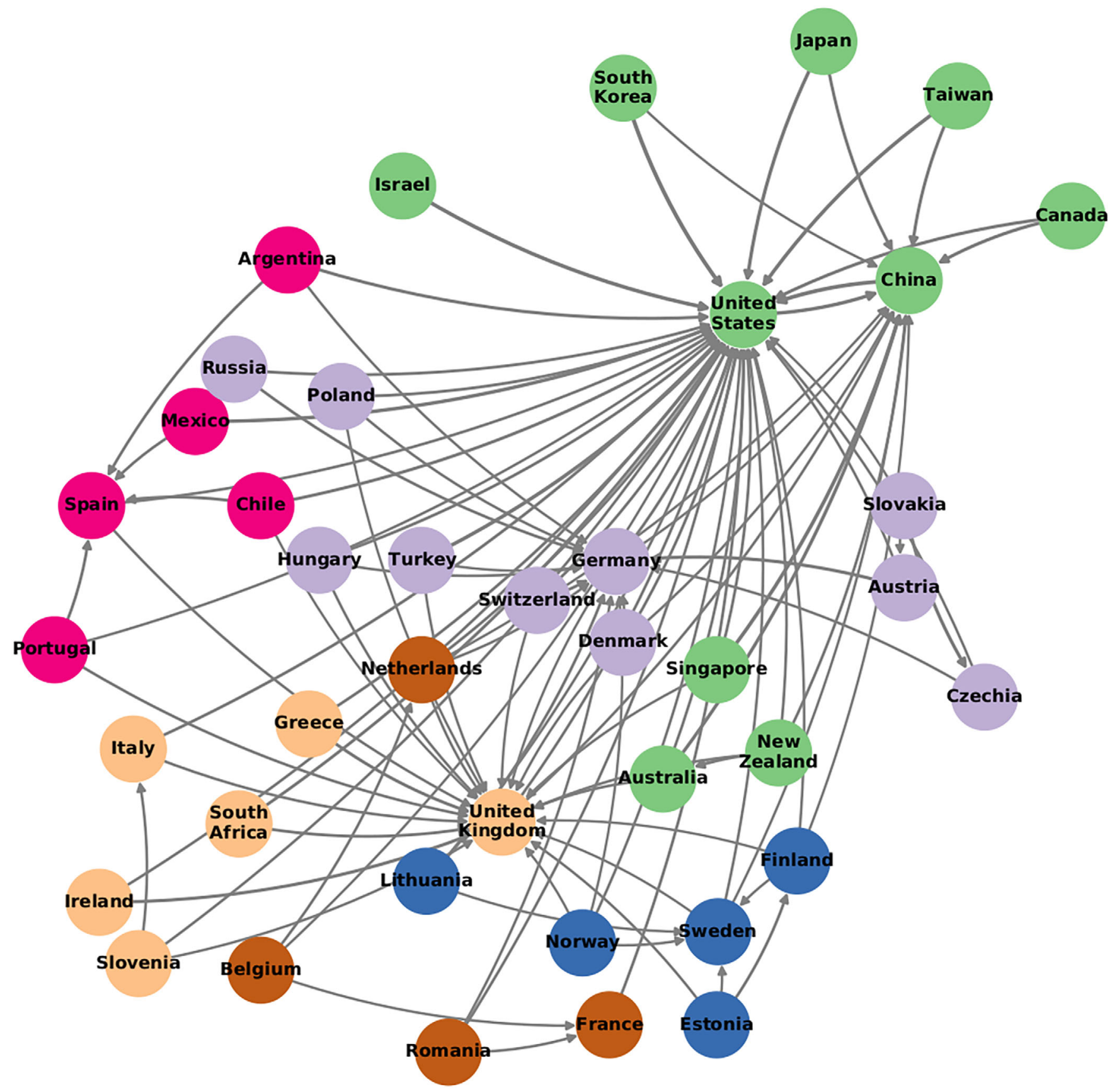

F I G U R E 5 Leiden communities of countries based on international co-affiliation (2016-2019 averages). The figure depicts communities of countries based on international co-affiliations of authors from a source (home) country. A source node is connected to another if a share not less than $10 \%$ of authors with international co-affiliation from the source hold their co-affiliation in the other country. Node colors indicate joint community based on the Leiden algorithm. Link width is proportional to the share of authors linked with the target country. Graph analysis conducted with code provided by Hagberg et al. (2008) and Rossetti, Milli, and Cazabet (2019) [Color figure can be viewed at wileyonlinelibrary.com] 


\subsection{The role of excellence initiatives}

The relatively sudden rise in the prevalence of multiple affiliations in the 2000s and the observed country differences may be related to reforms in the allocation of research funding that several countries have experienced during that period (RQ3).

We collected information on ExIns from Froumin and Lisyutkin (2015) and Geuna and Piolatto (2016). Some countries introduced several initiatives during the period of our study. For the purpose of our analysis we focus on the first introduction and only consider initiatives that involved substantial financial resources, that is, more than US\$1 million. We identified 17 countries that introduced ExIns between 2002 and 2018. Figure 1c/d above showed that before 2002 most countries had seen constant (or even slightly declining) shares of authors with multiple affiliations. Looking at Figure 6, which shows the trend in the share of multiple affiliations for countries that did not introduce ExIns (control group) and those that did (ExIn), we can indeed see how closely the trends correspond in those early years. The share of

(a)

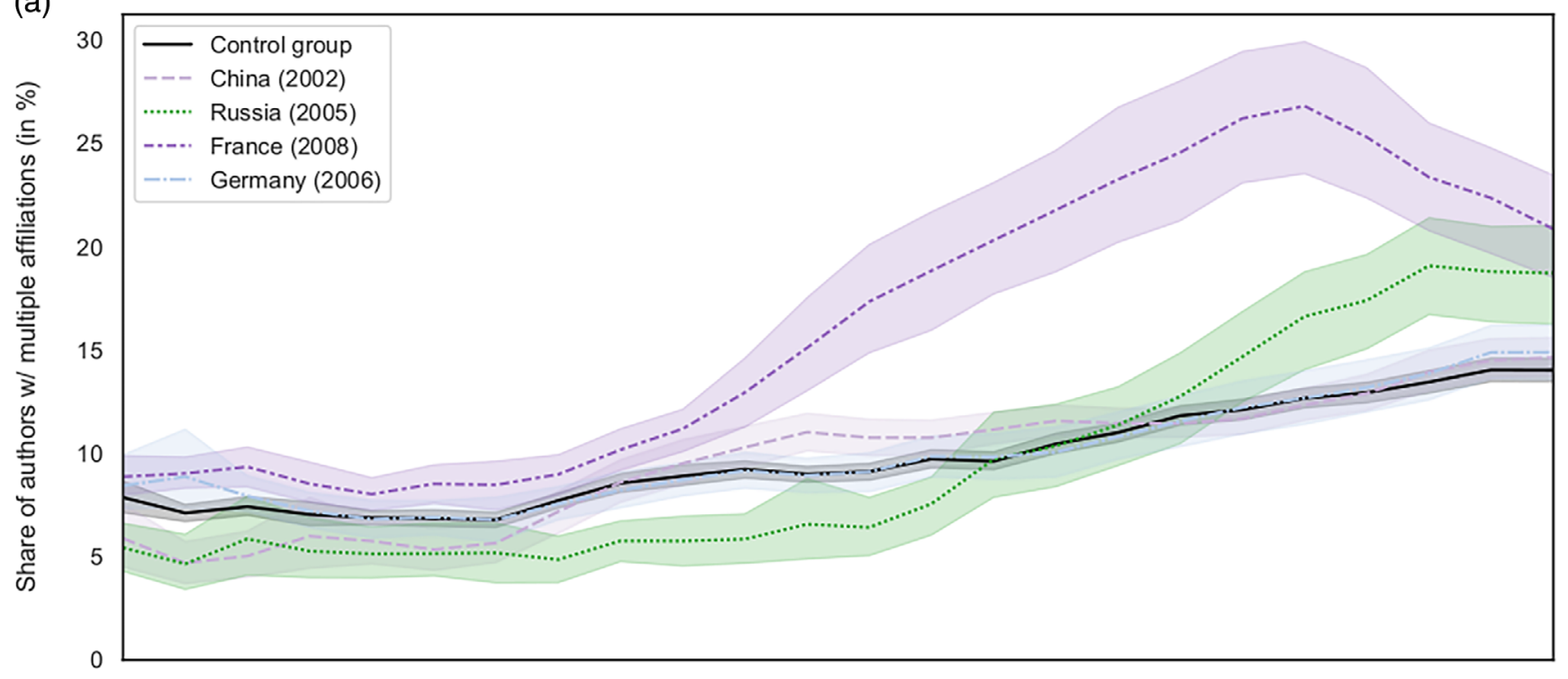

(b)

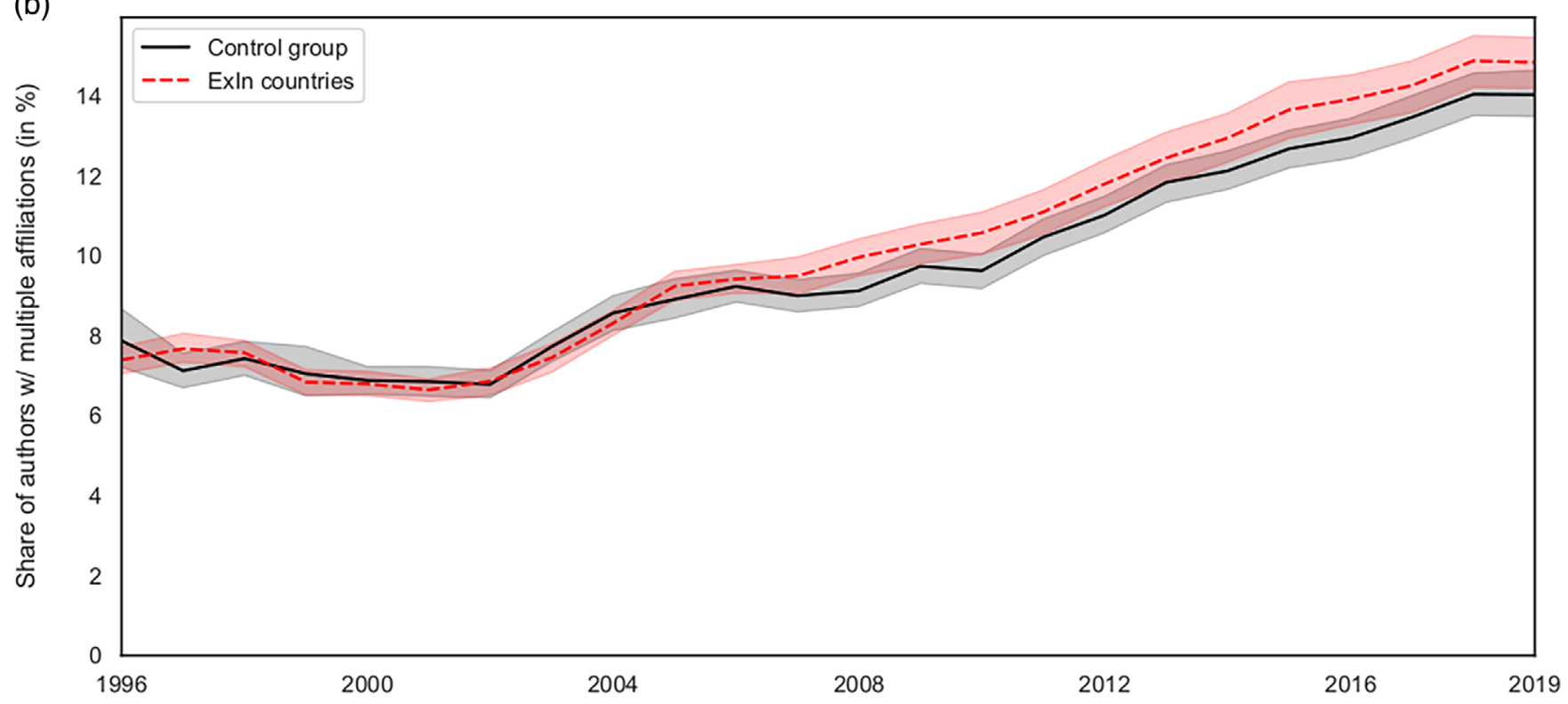

F I G U RE 6 Share of authors with multiple affiliations averaged over countries by year. The figure shows the share of authors with multiple affiliations accounting for countries' differing share in fields, $\bar{s}_{c, t}$. Shaded area indicates $95 \%$ confidence interval. Plot uses 111,038,114 author-field-country-year observations. See Tables A8 and A9 for precise values [Color figure can be viewed at wileyonlinelibrary.com] 


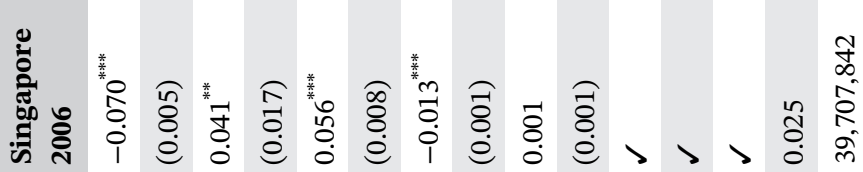

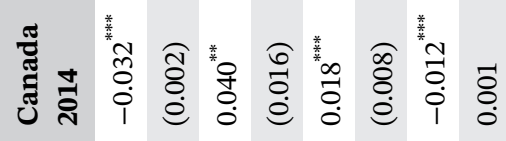

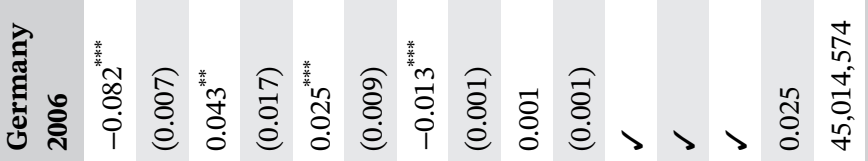

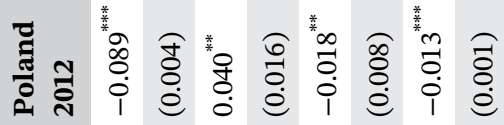

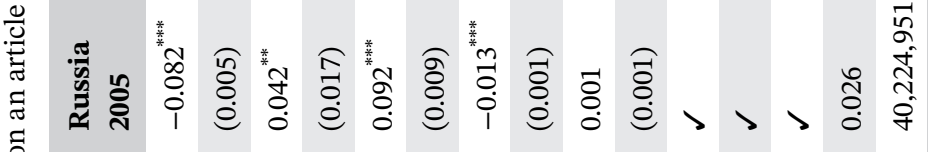

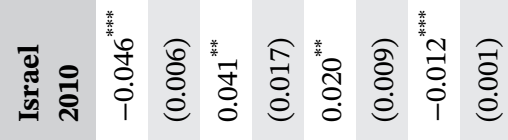

泀

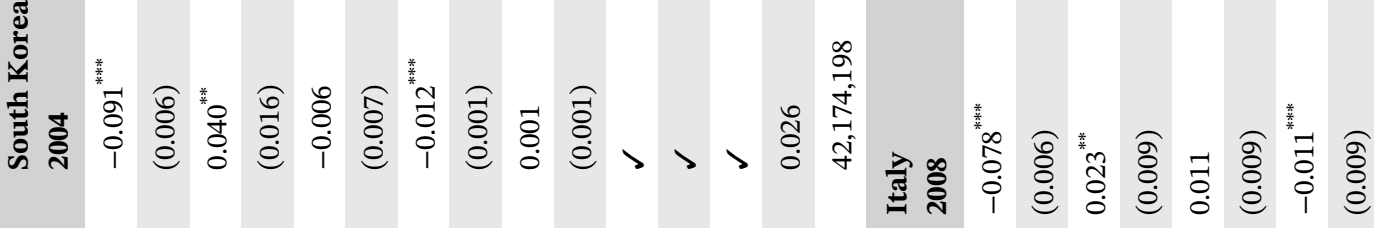

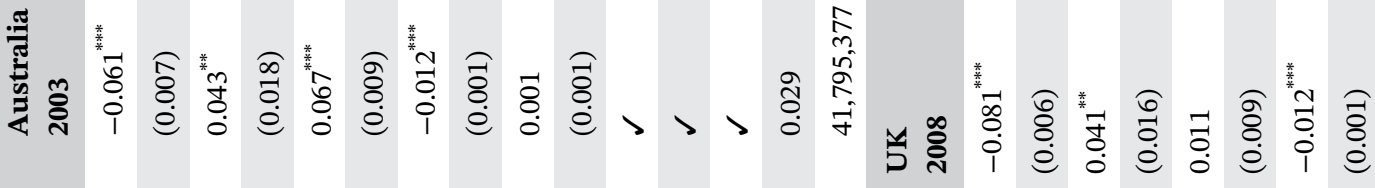

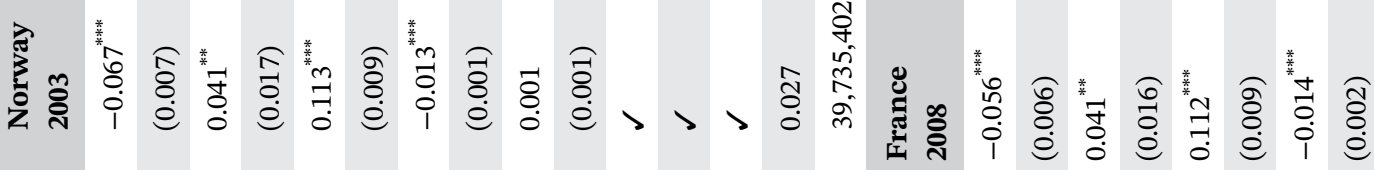

言

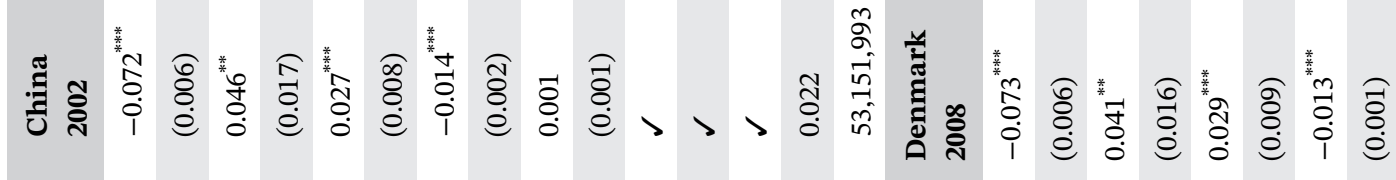

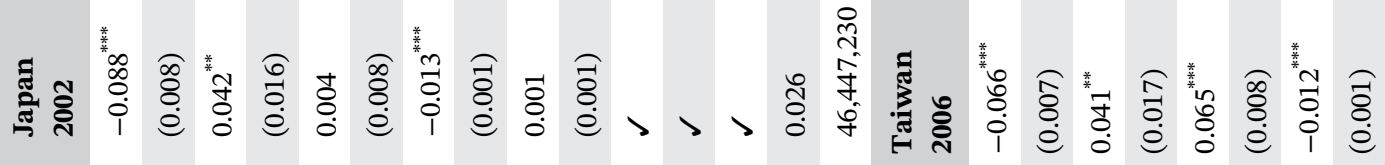

音

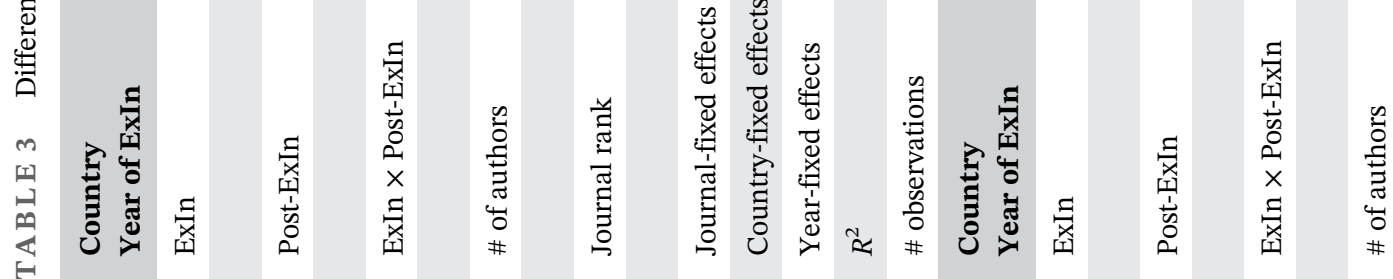




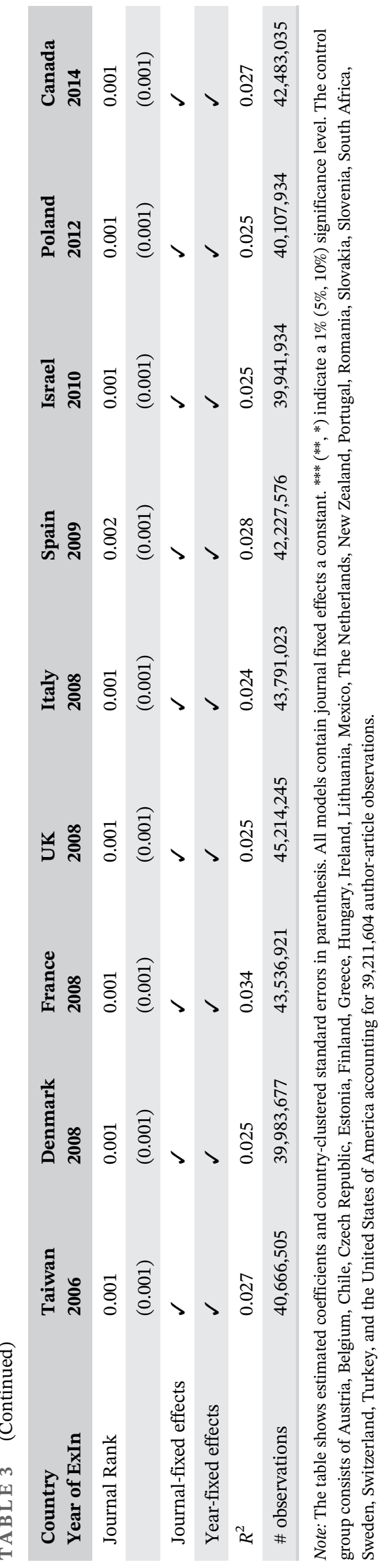

multiple affiliations started to increase in the early 2000s in countries with and without ExIns (see also Figure A5), though this increase appears stronger for the ExIn group. Figure 6a reports trends for selected ExIn countries and indicates some heterogeneity amongst these, with Germany staying close to the control group, while the Russia experiences an increase some years after the first ExIn.

The question arises whether the increase in multiple affiliations we can observe descriptively is indeed significantly stronger after the introduction of ExIns. To investigate this, we conduct difference-in-differences (DiD) analyses. In particular, we compare the likelihood that an author located in a country that introduced some kind of reform has multiple affiliations to the likelihood in a pool of authors located in control countries that did not significantly change their science funding structures. The DiD is the difference in this comparison before and after the year the reform came into effect.

We perform separate regressions at the author-article level for each ExIn country, as ExIns were introduced at different points in time. We hold the control group of countries constant, ${ }^{11}$ that is, we compare each ExIn country to the same set of control countries which corresponds to the control group in Figure 6. We estimate linear probability models (LPM) for the likelihood that an author has more than one affiliation listed on an article, and include the number of co-authors, and the timevarying SJR indicator as control variables. We also include journal, country, and year fixed effects.

Table 3 shows the results from the different country DiD models, reporting the year of the respective ExIns in the top row. Note that the unit of observation is articleauthor combination to account for the possibility of international co-authorship (i.e., an article to be assigned to more than one country) and multiple affiliations of several co-authors on an article. When interpreting the results, we need to note that there are likely announcement effects at play, which may result in behavioral changes prior the formal starting point of the reforms. Since the duration of the post-reform period is naturally longer for countries that introduced reforms earlier, we estimate models for the maximum post period (Table 3, and for a fixed window of one decade for those countries that implemented reforms prior to 2008 (Table 4).

Our analysis reveals a significant increase in multiple affiliations after the introduction of funding reforms in most of the 17 ExIn cases, where the results (for the full time window) show a positive and significant DiD (ExIn $\times$ Post-ExIn). The DiD estimates are largest in the case of France and Norway with an increase in the likelihood to have an author with multiple affiliations that is 11 percentage points higher than in the control group. Russia shows a higher likelihood of 9 percentage points 


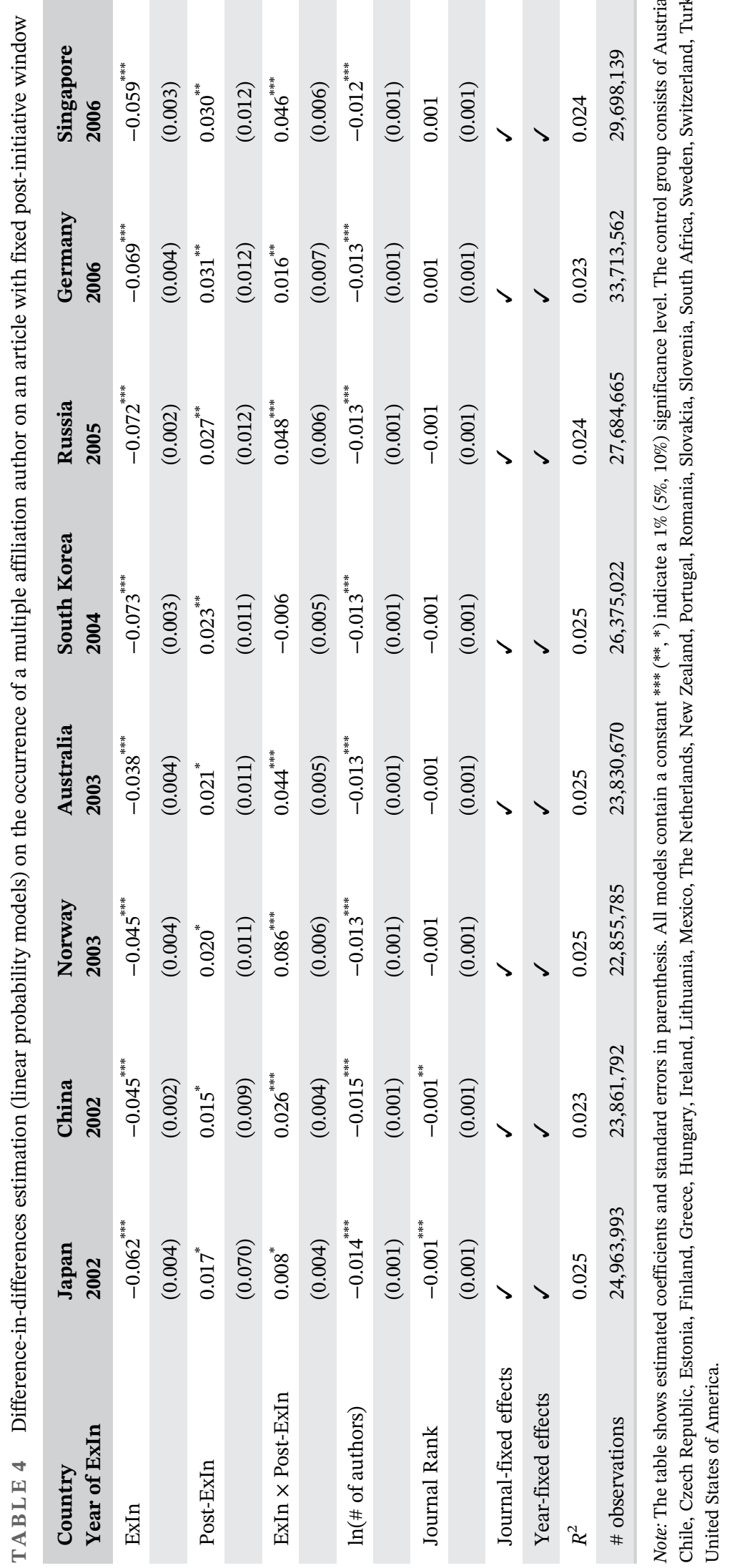

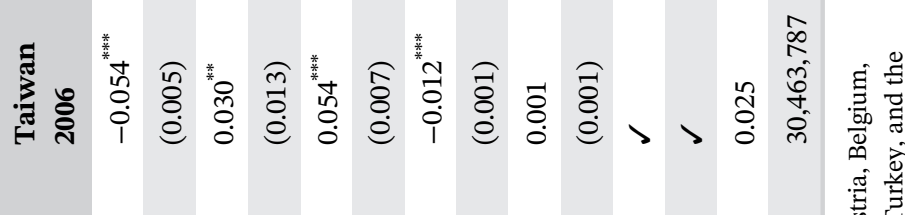


compared to the control group. Australia, Singapore, Taiwan and Spain show also significantly higher likelihoods in the occurrence of co-affiliated authors. Smaller differences can be found in Canada, China, Denmark, Israel, and Germany with around two to three percentage points higher increases than the control group. Comparing these results to those with a fixed time window (Table 4) shows that for Japan, the effect is larger in the short-run than in the long-run (where it is insignificant) unlike in other countries where multiple affiliations continue to increase. For the United Kingdom and Italy that have both undertaken similar research assessments of universities in 2008 (Geuna \& Piolatto, 2016), we do find a positive, but not statistically significant increase in the likelihood to see authors with multiple affiliations. This suggests that selective funding mechanisms and not research evaluation systems as such may be associated with multiple affiliations. We also do not find indications for treatment effects for South Korea. A negative DiD can be observed for Poland that-as the only ExIn country—sees significantly fewer authors with multiple affiliations after the implementation of ExIns. The control variables show that the number of authors on an article is negatively associated with the likelihood of seeing an author with multiple affiliations indicating that co-affiliations may also serve as a substitute for co-authorship.

\section{4 | CONCLUSIONS}

This paper analyzed affiliation information on published articles in 40 countries and 26 scientific fields over a 24 year period. We set out to answer three research questions: (RQ1) how multiple affiliations evolved over time in different countries and fields, (RQ2) whether these changes are corresponding to within or across sectors, and to domestic or international co-affiliations, and (RQ3) how they are impacted by ExIns.

Our findings regarding RQ1, reported in Section 3.1, showed increases in multiple affiliations across countries and fields. We showed that they are prevalent in all countries, with substantial increases in multiple affiliations in France and Russia amongst others, and no increase in the United States. The increasing prevalence of multiple affiliations suggests that fundamental changes to institutional conditions and the organization of science are at work. Previous research discussed changes in the complexity of science and increases in team sizes and cross-institutional collaborations on co-authored papers as its consequence and important coping mechanisms (Adams, Black, Clemmons, \& Stephan, 2005; Jones, Wuchty, \& Uzzi, 2008; Wuchty, Jones, \& Uzzi, 2007). The rise in multiple affiliations may be the reflection of another coping mechanism.
In response to RQ2, we documented different types of multiple affiliation in terms of the involved organizations and countries, reported in Section 3.2. We found that the majority of co-affiliations are between academic institutions, who drive the upwards trend. Co-affiliations between PROs and universities, in particular, have seen an increase. We further found that international coaffiliations account for slightly more than a fifth of all multiple affiliations and, while global network patterns of these international linkages changed over time, their relative importance did not increase. This indicates that the rise in multiple affiliations cannot be explained by a growth in international co-affiliations alone. Indeed, countries with higher increases have seen mainly more domestic co-affiliations.

Domestic science and higher education policies could be a critical driver behind these changes. To answer RQ3 we therefore investigated the effect of ExIns on multiple affiliations in difference-in-difference estimations, reported in Section 3.3. We show that the increase of authors with multiple affiliations has been particularly pronounced in countries that implemented substantial structural funding reforms over the past two decades. Examples include China (2002), Norway (2003), Russia (2005), Germany (2006), Singapore (2008), France (2008) and Israel (2010) (Butler, 2009; Salmi, 2016; Schiermeier, 2017). A shift in national research funding towards a higher concentration of resources and research output in fewer (elite) places (Hamann, 2018; Schiermeier \& Van Noorden, 2015) may constitute an incentive to affiliate with multiple institutions. In particular, co-affiliations to well-endowed institutions could provide a means for individual researchers to redress any imbalances in resource access. Some of the funding allocation mechanisms explicitly encourage collaboration between organizations which may result in authors listing all involved organizations on their publications as to share the output recognition between all of these. In addition, reorganization in science to gain visibility in international rankings has also been observed, and in the case of France can directly explain the increase in domestic co-affiliations following funding reforms (Paradeise, 2018).

While our analysis provides some new insights, there are other potential mechanisms we need to acknowledge. International co-affiliations could reflect traces of increased international mobility (Krieger, 2016; Schiermeier, 2017) and may provide an important source of productivityenhancing "home country linkages" (Baruffaldi \& Landoni, 2012), or make it easier for researchers to stay connected with previous institutions when internationally mobile. We find evidence of such traces in the co-affiliation communities, in particular the community centered around the United Kingdom. Such co-affiliations are likely 
beneficial for international research networks and knowledge exchange, contributing to brain circulation (Langa, 2018). Yet, the increase in multiple affiliations is largely driven by domestic, not international co-affiliations, and international mobility therefore likely a smaller contributing factor. An increase in international co-affiliations is generally seen in smaller science systems with perhaps weaker academic institutions. The United Kingdom and Switzerland are the two leading science nations with an above average share of international co-affiliations, which possibly reflects their status as a destination for foreign scholars and embeddedness in diaspora networks.

The increase in multiple affiliations may also be related to the growing importance of bibliometric indicators for research funding distribution more generally (Geuna, 1997). Institutions may have strong incentives to affiliate prolific researchers in order to increase their chances in funding competitions and to improve their ranking in institutional assessments. We indeed find a higher share of authors with multiple affiliations on articles in top journals compared to lower impact journals, which is indicative of such ranking mechanisms.

In terms of policy implications, blanket condemnation of multiple affiliations is not a good fix, as researchers and institutions can benefit. Yet, the increase in multiple affiliations also implies that counting publications simply based on listed affiliations distorts institutional performance measures and rankings, leading to difficulties in assigning research efforts and investment to individual universities. This adds to existing concerns about research metrics currently used to inform science policy (de Rijcke \& Rushforth, 2015). Multiple affiliations should therefore be taken into account in any bibliometric evaluations. Just as we acknowledge the contribution that multiple authors make to a scientific discovery, we may explicitly acknowledge the contribution of multiple institutions to the scientific work of an author. It may, however, require consensus about when the listing of an affiliation is justified based on its contribution.

Multiple affiliations may also reflect (or may be a symptom of) a decline of institutional support for academics, especially regarding resource constraints in university based research or the casualization of the academic profession, which require academics to seek resources and work roles outside their main institution. These consequences of resource concentration and stratification in higher education need to be considered by science funders.

Our analysis is, however, subject to some limitations. One limitation arises from heterogeneous standards on how affiliations are reported on a publication, which may affect how we assign authors to affiliations, leading to over- or under-counting of affiliations.
Other limitations arise from some of our assumptions. First, we assume that in case of multiple affiliations, the first listed affiliation is the main affiliation of an author. This might not always be the case, and consequently we may assign the wrong host country. The assignment of authors to countries also impacts the regression-based analysis which may result in an underestimation of the observed increases in countries with funding reforms if authors are being assigned to other countries based on first listing. Second, we assume that multiple affiliations on publications are co-occurring, when instead they may represent author mobility, with authors listing both their old and new employer to recognize the contribution of both. These limitations are inherent in bibliometric data and multiple affiliations therefore warrant further investigation using other types of data.

Finally, while we investigated ExIns as a potential driver of multiple affiliations, there may be other important factors driving these developments. We therefore encourage more research on this topic.

\section{5 | INSTRUCTIONS FOR THE REPLICATION OF THE ANALYSIS}

The programming code files to replicate the data collection, all calculations and the data analysis are available at https://github.com/Michael-E-Rose/The-Rise-of-MultipleInstitutional-Affiliations. We used the Python packages pybliometrics to retrieve the data (Rose \& Kitchin, 2019), pandas to manipulate the data (McKinney, 2010), seaborn for visualization (Waskom et al., 2020), and NetworkX for network analysis (Hagberg et al., 2008). Note that replication requires subscription to Scopus. If random sampling was applied, the seed was always equal to zero.

\section{ACKNOWLEDGMENT}

Open Access funding enabled and organized by Projekt DEAL. WOA Institution: Technische Universitat Munchen. Blended DEAL: Projekt DEAL.

\section{ORCID}

Hanna Hottenrott (10 https://orcid.org/0000-0002-15848106

Michael E. Rose (i) https://orcid.org/0000-0002-4128-4236 Cornelia Lawson (1) https://orcid.org/0000-0002-1262-

5142

\section{ENDNOTES}

${ }^{1}$ See www.natureindex.com. 
${ }^{2}$ See blog.scopus.com.

${ }^{3}$ We use only research articles, reviews, notes, conference proceedings, in-press articles or short articles, as classified by Scopus.

${ }^{4}$ We obtain the scores from https://www.scimagojr.com/ as of January 2019.

5 The data was downloaded between March 2020 and September 2020.

${ }^{6}$ Affiliations are missing in the Scopus database when, for example, affiliation information is too hard to parse automatically.

${ }^{7}$ When generating author profiles, the Scopus algorithm is conservative and prefers "split profiles" over "merge profiles" (Moed, Aisati, \& Plume, 2013), that is, it rather casts too many profiles for the same researcher than lumping publications of many different researchers into one profile. Accordingly, Baas, Schotten, Plume, Côté, and Karimi (2020) estimate the precision of Scopus author profiles (the absence of documents that belong to someone else) equal to $98.1 \%$ and recall (the absence of documents that belong to this author) equal to $94.4 \%$. Precision and recall do however correlate with origin of authors. This is likely the reason behind the high share of Chinese authors (read: author profiles) in our samples (Table A1). To check for any bias introduced by this, we compare figures for the full sample to a subsample excluding China and see only very minor differences. To illustrate this, Figure A6 plots the share of authors with multiple affiliations by field, excluding China. The difference to Figure A2 that shows the share of authors with multiple affiliations by field for the full sample is minimal.

${ }^{8}$ Appendix B details two refinements to the affiliation information aimed at avoiding to falsely classifying an additional address as affiliation information.

${ }^{9}$ A random examination of 100 affiliation profiles with unknown type suggests the following distribution: university and colleges: $40 \%$, companies: $20 \%$, hospitals: $12 \%$, governmental organizations: $9 \%$, NGOs: $4 \%$, unclassified: $11 \%$.

10 The share of international co-affiliations also differs by field. See Table A7. The shares are highest in Economics (55.2\% on average over all years), Business (51.5\%) and Decision Sciences (48.3\%), and lowest in Nursing (19.9\% and Health (24.2\%).

${ }^{11}$ Countries in the control group are Austria, Belgium, Chile, Czechia, Estonia, Finland, Greece, Hungary, Ireland, Lithuania, Mexico, The Netherlands, New Zealand, Portugal, Romania, Slovakia, Slovenia, South Africa, Sweden, Switzerland, Turkey and the United States of America.

\section{REFERENCES}

Adams, J. D., Black, G. C., Clemmons, J. R., \& Stephan, P. E. (2005). Scientific teams and institutional collaborations: Evidence from U.S. universities, 1981-1999. Research Policy, 34(3), 259-285.

Agasisti, T., Shibanova, E., Platonova, D., \& Lisyutkin, M. (2020). The Russian Excellence Initiative for higher education: A nonparametric evaluation of short-term results. International Transactions in Operational Research, 27(4), 1911-1929.

Aghion, P., Dewatripont, M., Hoxby, C., Mas-Colell, A., \& Sapir, A. (2014). The governance and performance of universities: Evidence from Europe and the US. Economic Policy, 25(61), 7-59.
Baas, J., Schotten, M., Plume, A., Côté, G., \& Karimi, R. (2020). Scopus as a curated, high-quality bibliometric data source for academic research in quantitative science studies. Quantitative Science Studies, 1(1), 377-386.

Baruffaldi, S. H., \& Landoni, P. (2012). Return mobility and scientific productivity of researchers working abroad: The role of home country linkages. Research Policy, 41(9), 1655-1665.

Benito, M., Gil, P., \& Romera, R. (2019). Funding, is it key for standing out in the university rankings? Scientometrics, 121(2), 771-792.

Bhattacharjee, Y. (2011). Saudi universities offer cash in exchange for academic prestige. Science, 334(6061), 1344-1345.

Bornmann, L. (2016). Is the promotion of research reflected in bibliometric data? A network analysis of highly cited papers on the clusters of excellence supported under the excellence initiative in Germany. Scientometrics, 107(3), 1041-1061.

Bornmann, L., \& Bauer, J. (2015). Which of the world's institutions employ the most highly cited researchers? An analysis of the data from highlycited.com. Journal of the Association for Information Science and Technology, 66(10), 2146-2148.

Butler, D. (2009). French research wins huge cash boost. Nature, $462,838$.

Civera, A., Lehmann, E. E., Paleari, S., \& Stockinger, S. A. (2020). Higher education policy: Why hope for quality when rewarding quantity? Research Policy, 49(8), 104083.

de Rijcke, S., \& Rushforth, A. (2015). To intervene or not to intervene; is that the question? On the role of scientometrics in research evaluation. Journal of the Association for Information Science and Technology, 66(9), 1954-1958.

Froumin, I., \& Lisyutkin, M. (2015). Excellence-driven policies and initiatives in the context of bologna process: Rationale, design, implementation and outcomes. In A. Curaj, L. Matei, R. Pricopie, J. Salmi, \& P. Scott (Eds.), The European higher education area. Springer.

Fu, Y., Baker, D., \& Zhang, L. (2020). Engineering a world class university? The impact of Taiwan's World Class University Project on scientific productivity. Higher Education Policy, 33, 555-570.

Geuna, A. (1997). Allocation of funds and research output: The case of UK universities. Revue d'Économie Industrielle, 79(1), 143-162.

Geuna, A., \& Piolatto, M. (2016). Research assessment in the UKand Italy: Costly and difficult, but probably worth it (at least for a while). Research Policy, 45(1), 260-271.

González-Pereira, B., Guerrero-Bote, V. P., \& Moya-Anegón, F. (2010). A new approach to the metric of journals' scientific prestige: The SJR indicator. Journal of Informetrics, 4(3), 379-391.

Hagberg, A. A., Schult, D. A., \& Swart, P. J. (2008). Exploring network structure, dynamics, and function using NetworkX, In G. Varoquaux, T. Vaught, \& J. Millman (Eds.), Proceedings of the 7th Python in Science Conference (SciPy2008) (pp. 11-15). Pasadena, CA USA Aug 2008. https://networkx.org/documentation/ stable//citing.html.

Hamann, J. (2018). The production of research elites: Research performance assessment in the United Kingdom. In R. Bloch, A. Mitterle, C. Paradeise, \& T. Peter (Eds.), Universities and the production of elites: Discourses, policies, and strategies of excellence and stratification in higher education (pp. 175-199). Cham: Springer International Publishing.

Hicks, D., \& Katz, J. S. (1996). Science policy for a highly collaborative science system. Science and Public Policy, 23(1), 39-44. 
Hottenrott, H., \& Lawson, C. (2017). A first look at multiple institutional affiliations: A study of authors in Germany, Japan and the UK. Scientometrics, 111, 285-295.

Jones, B. F., Wuchty, S., \& Uzzi, B. (2008). Multi-university research teams: Shifting impact, geography, and stratification in science. Science, 322(5905), 1259-1262.

Katz, J., \& Martin, B. R. (1997). What is research collaboration? Research Policy, 26(1), 1-18.

Krieger, A. (2016). Germany: Equality or excellence. Nature, 537, 12-13.

Langa, P. V. (2018). African diaspora and its multiple academic affiliations: Curtailing brain drain in African higher education through translocal academic engagement. Journal of Higher Education in Africa, 16(1/2), 51-76.

$\mathrm{Li}, \mathrm{J}$. (2016). What we learn from the shifts in highly cited data from 2001 to 2014 ? Scientometrics, 108, 57-82.

Matveeva, N., \& Ferligoj, A. (2020). Scientific collaboration in Russian universities before and after the excellence initiative project 5-100. Scientometrics, 124(3), 2383-2407.

McKinney, W. (2010). Data structures for statistical computing in Python. In S. van der Walt \& J. Millman (Eds.), Proceedings of the 9th Python in Science Conference (pp. 51-56).

Menter, M., Lehmann, E. E., \& Klarl, T. (2018). In search of excellence: A case study of the first excellence initiative of Germany. Journal of Business Economics, 88(9), 1105-1132.

Meyer, J.-B., \& Wattiaux, J.-P. (2006). Diaspora knowledge networks: Vanishing doubts and increasing evidence. International Journal on Multicultural Societies, 8(1), 4-24.

Miguelez, E., \& Noumedem Temgoua, C. (2020). Inventor migration and knowledge flows: A two-way communication channel? Research Policy, 49(9), 103914.

Moed, H. F., Aisati, M., \& Plume, A. (2013). Studying scientific migration in Scopus. Scientometrics, 94(3), 929-942.

Mongeon, P., \& Paul-Hus, A. (2016). The journal coverage of Web of Science and Scopus: A comparative analysis. Scientometrics, 106, 213-228.

Paradeise, C. (2018). How effective have reform policies been in redesigning the French higher education and research system? In R. Bloch, A. Mitterle, C. Paradeise, \& T. Peter (Eds.), Universities and the production of elites: Discourses, policies, and strategies of excellence and stratification in higher education (pp. 103125). Cham: Springer International Publishing.

Rose, M. E., \& Kitchin, J. R. (2019). pybliometrics: Scriptable bibliometrics using a Python interface to Scopus. SoftwareX, 10, 100263.

Rossetti, G., Milli, L., \& Cazabet, R. (2019). CDLIB: A python library to extract, compare and evaluate communities from complex networks. Applied Network Science, 4, 52-78.

Salmi, J. (2016). Excellence strategies and the creation of worldclass universities. In N. C. Liu, Y. Cheng, \& Q. Wang (Eds.), Matching visibility and performance (pp. 13-48). Leiden, The Netherlands: Brill|Sense.
Schiermeier, Q. (2017). Academic excellence: Golden Germany. Nature, 549, 119-121.

Schiermeier, Q., \& Van Noorden, R. (2015). Germany claims success for elite universities drive. Nature, 525, 168-169.

Stephan, P. E. (2012). How Economics Shapes Science. Cambridge, MA: Harvard University Press.

Traag, V., Waltman, L., \& van Eck, N. (2019). From Louvain to Leiden: Guaranteeing well-connected communities. Scientific Reports, 9, 5233.

Turko, T., Bakhturin, G., Bagan, V., Poloskov, S., \& Gudym, D. (2016). Influence of the program "5-top-100" on the publication activity of Russian universities. Scientometrics, 109(2), 769-782.

Van Der Wende, M. (2015). International academic mobility: Towards a concentration of the minds in Europe. European Review, 23(S1), S70-S88.

Waskom, M., Botvinnik, O., O'Kane, D., Hobson, P., Ostblom, J., Lukauskas, S., Gemperline, D. C., Augspurger, T., Halchenko, Y., Cole, J. B., Warmenhoven, J., Ruiter, J. D., Pye, C., Hoyer, S., Vanderplas, J., Villalba, S., Kunter, G., Quintero, E., Bachant, P., ... Qalieh, A. (2020). mwaskom/seaborn. Zenodo.

Way, S. F., Morgan, A. C., Larremore, D. B., \& Clauset, A. (2019). Productivity, prominence, and the effects of academic environment. Proceedings of the National Academy of Sciences, 116(22), 10729-10733.

Wuchty, S., Jones, B. F., \& Uzzi, B. (2007). The increasing dominance of teams in production of knowledge. Science, 316(5827), 1036-1039.

Xin, H. (2006). Frustrations mount over China's high-priced hunt for trophy professors. Science, 313(5794), 1721-1723.

Zhang, H., Patton, D., \& Kenney, M. (2013). Building global-class universities: Assessing the impact of the 985 project. Research Policy, 42(3), 765-775.

Zong, X., \& Zhang, W. (2019). Establishing world-class universities in China: Deploying a quasi-experimental design to evaluate the net effects of Project 985. Studies in Higher Education, 44 (3), 417-431.

\section{SUPPORTING INFORMATION}

Additional supporting information may be found online in the Supporting Information section at the end of this article.

How to cite this article: Hottenrott $\mathrm{H}$, Rose ME, Lawson C. The rise of multiple institutional affiliations in academia. J Assoc Inf Sci Technol. 2021;1-20. https://doi.org/10.1002/asi.24472 